OPEN ACCESS

Edited by:

Inmaculada Maria

Gonzalez-Gonzalez,

University of Central Lancashire,

United Kingdom

Reviewed by:

Martin Heine,

Johannes Gutenberg University

Mainz, Germany

Sandra Jurado,

Instituto de Neurociencias de

Alicante (IN), Spain

*Correspondence:

Jonathan G. Hanley

jon.hanley@bristol.ac.uk

Received: 11 September 2018 Accepted: 13 November 2018 Published: 05 December 2018

Citation:

Parkinson GT and Hanley JG (2018) Mechanisms of AMPA Receptor Endosomal Sorting.

Front. Mol. Neurosci. 11:440. doi: 10.3389/fnmol.2018.00440

\section{Mechanisms of AMPA Receptor Endosomal Sorting}

\author{
Gabrielle T. Parkinson and Jonathan G. Hanley* \\ Centre for Synaptic Plasticity and School of Biochemistry, University of Bristol, Bristol, United Kingdom
}

The regulation of synaptic AMPA receptors (AMPARs) is critical for excitatory synaptic transmission, synaptic plasticity and the consequent formation of neural circuits during brain development and their modification during learning and memory processes. The number of synaptic AMPARs is regulated through endocytosis, exocytosis and endosomal sorting that results in recycling back to the plasma membrane or degradation in the lysosome. Hence, endo-lysosomal sorting is vitally important in maintaining AMPAR expression at the synapse, and the dynamic regulation of these trafficking events is a key component of synaptic plasticity. A reduction in synaptic strength such as in long-term depression (LTD) involves AMPAR sorting to lysosomes to reduce synaptic AMPAR number, whereas long-term potentiation (LTP) involves an increase in AMPAR recycling to increase the number of AMPARs at synapses. Here, we review our current understanding of the endosomal trafficking routes taken by AMPARs, and the mechanisms involved in AMPAR endosomal sorting, focussing on the numerous AMPAR associated proteins that have been implicated in this complex process. We also discuss how these events are dysregulated in brain disorders.

Keywords: endosome, synapse, trafficking, glutamate receptor, LTD (long term depression), LTP (long term potentiation), synaptic plasticity

\section{INTRODUCTION}

AMPA receptors (AMPARs) are ionotropic glutamate receptors that comprise hetero-tetrameric assemblies of subunits GluA1-4. Since AMPARs facilitate the majority of fast excitatory neurotransmission in the brain, changes in their abundance at synapses can significantly strengthen or weaken synaptic transmission (Malinow and Malenka, 2002). Long-term synaptic plasticity is thought to be a molecular and cellular correlate of learning and memory by playing a critical role in experience-dependent tuning of neural circuits that encode memories or behaviors (Mayford et al., 2012; Takeuchi et al., 2013). A decrease in synaptic strength involves a removal of AMPARs from synapses in long-term depression (LTD), whereas an increase in the number of synaptic AMPARs leads to increased synaptic strength known as long-term potentiation (LTP; Bredt and Nicholl, 2003; Henley and Wilkinson, 2016). In addition, homeostatic plasticity, also known as synaptic scaling, involves a cell-wide adjustment of synaptic strength to maintain a stable output of a particular neuron during changes in neuronal circuit activity (Fernandes and Carvalho, 2016).

Both basal maintenance and activity-dependent alterations of synaptic AMPAR expression are underpinned by the regulation of AMPAR trafficking through endosomal compartments within neurons (Hirling, 2009; Henley and Wilkinson, 2016). The constitutive and activity-dependent trafficking of AMPARs from the synaptic plasma membrane into intracellular compartments occurs predominantly through clathrin-mediated endocytosis 
(CME; Man et al., 2000; Cosker and Segal, 2014). Following internalization, cargo is trafficked to early endosomes (EEs) where it is sorted into distinct pathways. There are 3 possible routes that AMPARs can take from EEs: (1) a recycling path that returns cargo back to the plasma membrane via recycling endosomes (REs; Figure 1-step 2; van der Sluijs and Hoogenraad, 2011); (2) EEs can mature into late endosomes/multivesicular bodies (LEs/MVBs) and subsequently lysosomes to degrade the cargo contained therein (Figure 1-step 4; Hu et al., 2015); (3) cargo can be targeted from EEs back to the biosynthetic machinery for further post-translational modification (PTM; Figure 1-step 3; Hirling, 2009; van der Sluijs and Hoogenraad, 2011; Burd and Cullen, 2014).

It is estimated that approximately $60 \%-75 \%$ of all AMPARs in hippocampal neurons are intracellular (Richmond et al., 1996; Greger et al., 2003), and this internal pool contributes substantially to the regulation of surface AMPAR expression during constitutive and activity-dependent trafficking events. Indeed, an intracellular pool of AMPARs is proposed to function as a source of AMPARs for AMPAR synaptic delivery during LTP (Park et al., 2004; Kneussel and Hausrat, 2016) and forward AMPAR trafficking from these pools has been proposed to be negatively regulated during LTD (Lee et al., 2004; Citri et al., 2010).

AMPAR and NMDA receptor (NMDAR) stimulation have been shown to induce AMPAR trafficking to lysosomal compartments and their subsequent degradation (Ehlers, 2000; Lee et al., 2004) and blocking AMPAR lysosomal targeting inhibits hippocampal LTD (Fernández-Monreal et al., 2012). Thus, it is generally thought that increasing synaptic AMPARs during LTP-driven trafficking events requires the sorting of AMPARs into REs so that they return to the plasma membrane, whereas decreasing synaptic AMPARs during LTD plasticity events requires the retention of AMPARs at intracellular compartments and/or the active sorting of AMPARs towards LEs/lysosomes to be degraded.

These observations are complicated by the fact that individual AMPAR subunits confer different functional properties as well as different trafficking behaviors to the receptor complex (Bredt and Nicholl, 2003; Shepherd and Huganir, 2007; Henley and Wilkinson, 2016). Distinct trafficking mechanisms depend on the heterogeneity of AMPAR subunit C-terminal domains and the resultant diversity in interacting proteins (Passafaro et al., 2001; Lee et al., 2003; Anggono and Huganir, 2012). The majority of AMPARs are an assembly of two heterodimers of GluA2 and GluA1 or to a lesser extent GluA2 and GluA3 (Wenthold et al., 1996; Lu et al., 2009) and can only become incorporated into the synaptic membrane in tetrameric assemblies (Grunwald and Kaplan, 2003). The presence of GluA2 is of functional importance because it confers $\mathrm{Ca}^{2+}$ impermeability to the AMPAR channel (Isaac et al., 2007). GluA2 subunit largely determines constitutive and activitydependent AMPAR endocytosis and recycling under resting

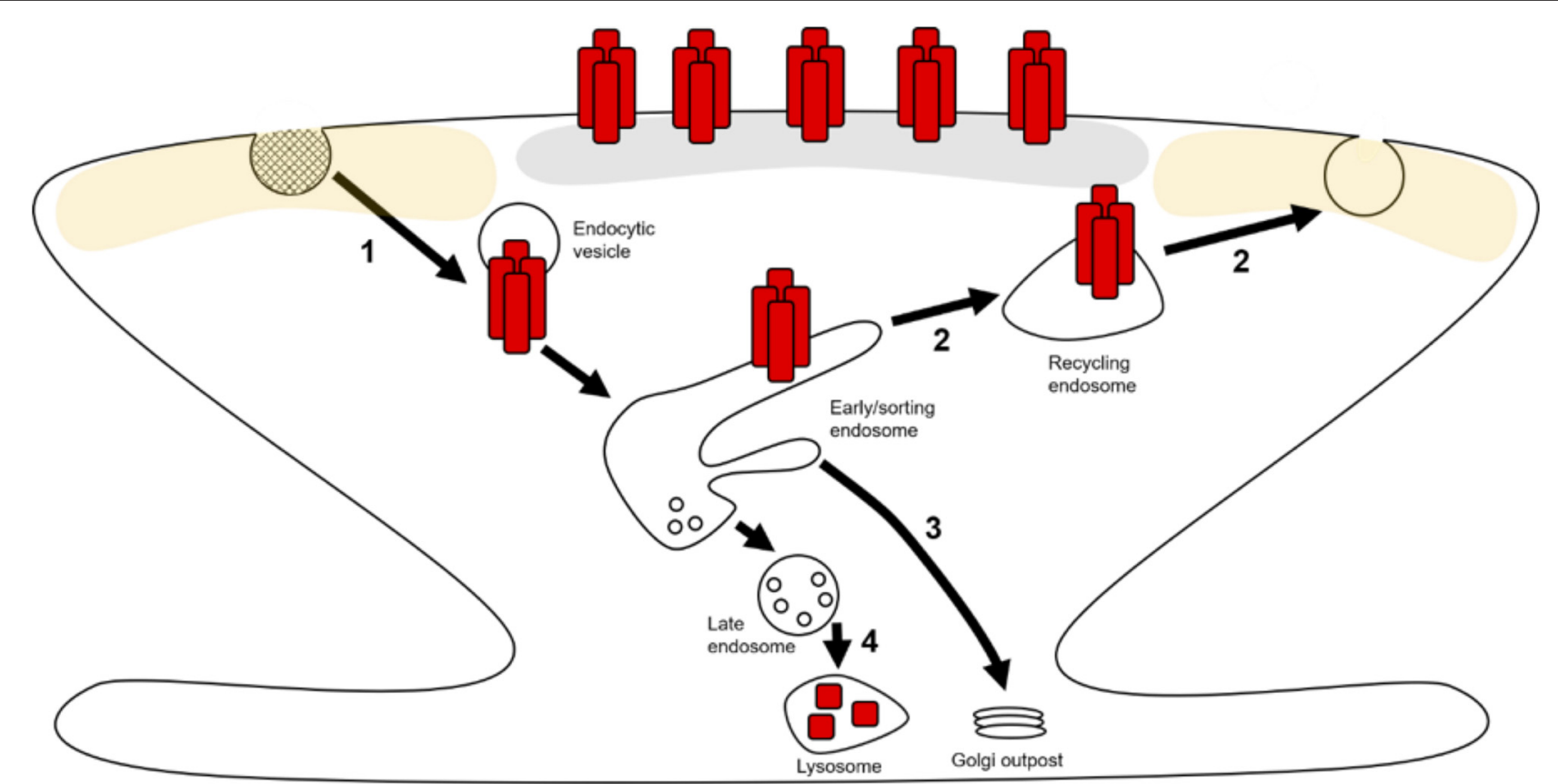

FIGURE 1 | AMPA receptor (AMPAR) trafficking in dendritic spines and local dendrites. AMPARs (red rectangles) can laterally move along extrasynaptic (yellow shaded area) and dendritic plasma membranes where they can be captured and stabilized at the postsynaptic density (PSD; gray area). AMPARs can then be retrieved from the surface by endocytosis (1) and trafficked to early endosomes (EEs). At these EEs, receptors are sorted into distinct trafficking pathways. Receptors can recycle back to the plasma membrane through tubular domains on EEs via exocytosis at extrasynaptic zones (2). Through these tubular domains, AMPARs can also be retrogradely trafficked to Golgi outposts (3). The vesicular domains on EEs mature into late endosomes (LEs), which subsequently fuse with lysosomes resulting in receptor degradation (4). 
conditions and sorting to lysosomes for degradation upon LTD induction. The presence of GluA3 subunit is also thought to promote lysosomal targeting (Lee et al., 2004). On the other hand, GluA1 subunits regulate LTP-induced AMPAR recycling (Hayashi et al., 2000; Shi et al., 2001; Park et al., 2004). These results are corroborated by the observation that the rate of basal GluA1 plasma membrane insertion is slow and enhanced by NMDAR activation, whereas GluA2-containing AMPAR exocytosis is faster under resting conditions and unaffected by NMDAR activity (Passafaro et al., 2001; Shi et al., 2001).

\section{NEURONAL ENDOSOMAL ORGANIZATION}

It is generally thought that neurons utilize the same endosomal sorting system as non-neuronal cells (Figure 1). Nevertheless, due to their distinct morphology and cargo, neurons exhibit some unique aspects of endosomal compartment organization and regulatory trafficking mechanisms (Kennedy and Ehlers, 2006; Yap and Winckler, 2012).

Synaptic proteins, such as AMPARs, are concentrated and stabilized in dendritic spines in specialized structures called postsynaptic densities (PSDs) through interactions with scaffolding proteins. Prior to endocytosis, AMPARs must dissociate from the PSD scaffold, and are thought to move laterally to endocytic zones localized adjacent to the PSD (Ashby et al., 2004; Lu et al., 2007; Tao-Cheng et al., 2011; Opazo et al., 2012). The mechanisms of endocytosis per se will not be discussed in detail here. Once internalized, AMPARs enter EEs, which are short-lived endomembrane structures where cargo is sorted into distinct endosomal microdomains to be recycled, retrogradely trafficked or degraded (Scott et al., 2014). EEs in mammalian cells have morphologically distinct subdomains; tubular structures are thought to provide a greater surface area to volume ratio to capture the majority of membrane cargo for default recycling (Maxfield and McGraw, 2004; Collinet et al., 2010). Alternatively, some tubular domains are specialized to direct cargo back to the TGN (Burd and Cullen, 2014). In contrast, cargo marked for degradation are sorted into more bulbous regions that rapidly acidify and mature into LEs (Huotari and Helenius, 2011). Finally, LEs fuse with lysosomes, where hydrolases, proteases and lipases break down cargo in the intraluminal vesicles (Hu et al., 2015).

Neuronal EEs are found throughout the soma and dendrites, but are largely absent from axons (Ehlers, 2000; Wilson et al., 2000). In dendrites, approximately $70 \%$ of intracellular membrane structures are situated within or at the base of spines and $36 \%-56 \%$ of spines contain an endosomal structure, depending on developmental age (Cooney et al., 2002; Park et al., 2006; Kennedy et al., 2010). Large EEs can serve approximately 20 spines, although this number is smaller in the case of larger, more mature spines. REs and LEs are similarly localized throughout dendrites and the soma (Park et al., 2006; Von Bartheld and Altick, 2011). Indeed, it has been shown that the positioning of recycling endosomal compartments at the base of spines is crucial for synaptic AMPAR delivery and for spine morphology (Park et al., 2006; Esteves da Silva et al., 2015). Lysosomes were initially believed to be somatically restricted, but recent evidence has demonstrated that functional lysosomes are present in distal dendrites and can be recruited to spines during neuronal activity to degrade important cargo, including AMPARs (Goo et al., 2017; Padamsey et al., 2017). These specializations are thought to be necessary to quickly regulate endosomal trafficking events in the complex neuronal architecture (Hanus and Schuman, 2013).

\section{DETAILED MOLECULAR MECHANISMS OF AMPAR ENDOSOMAL TRAFFICKING}

Due to the interconnected nature of the endomembrane system, it is likely that certain proteins function at multiple endosomal compartments to mediate the progression of one trafficking event to the next or indeed travel with cargo throughout intracellular membranes. Cargo-associated proteins involved in trafficking often contain various protein-binding domains, membrane-binding domains, GTPase regulatory domains or actin regulatory domains to mediate the complex interplay between membrane curvature, signaling cascades and the actin cytoskeleton that are necessary for coordinating membrane fission and fusion between endosomal compartments (Figure 2). The specific targeting of cargo from one membrane compartment to the next is determined by the interactions between these regulatory proteins and the cargo itself (Bonifacino and Glick, 2004).

\section{Endosomal Entry}

For AMPARs to enter the endosomal system they must be released from their synaptic stabilizing proteins such as GRIP and PSD-95 (Bats et al., 2007). The majority of LTD-induced AMPAR internalization is believed to occur through CME (Man et al., 2000; Collingridge et al., 2010), and it has been suggested that constitutive internalization may occur via clathrin-independent endocytosis (Glebov et al., 2015; Fujii et al., 2017). There are a number of proteins that interact with AMPARs and the endocytic machinery for effective, activity-dependent, subunitselective AMPAR internalization, the details of which are beyond the scope of this review (for a detailed review see Anggono and Huganir, 2012).

Specific mechanisms of AMPAR entry into the endosomal system after endocytosis are poorly understood, but the process requires Rab5 and EE antigen 1 (EEA1). EEA1 is a vesicle tethering protein that associates with phosphatidylinositol 3-phosphate (PI(3)P) in the EE membrane (Gaullier et al., 2000) and binds Rab5 on an endocytic vesicle to facilitate membrane fusion and hence incorporation of endocytic cargo into EEs (Simonsen et al., 1998; Murray et al., 2016). EEA1 inhibition or downregulation results in increased AMPAR conductance and GluA1-containing AMPAR surface expression (Selak et al., 2006; Xu and Pozzo-Miller, 2017). Rab5 overexpression results in increased EE to lysosome maturation, and increased lysosomal degradation of AMPARs (Lai et al., 2009). Consistent with these observations, Rab5 activity is essential for LTD (Brown et al., 2005), and the Rab5 GEF, RIN1, has recently been shown to facilitate activity-dependent AMPAR internalization (Szíber et al., 2017). However, it has not been definitively 


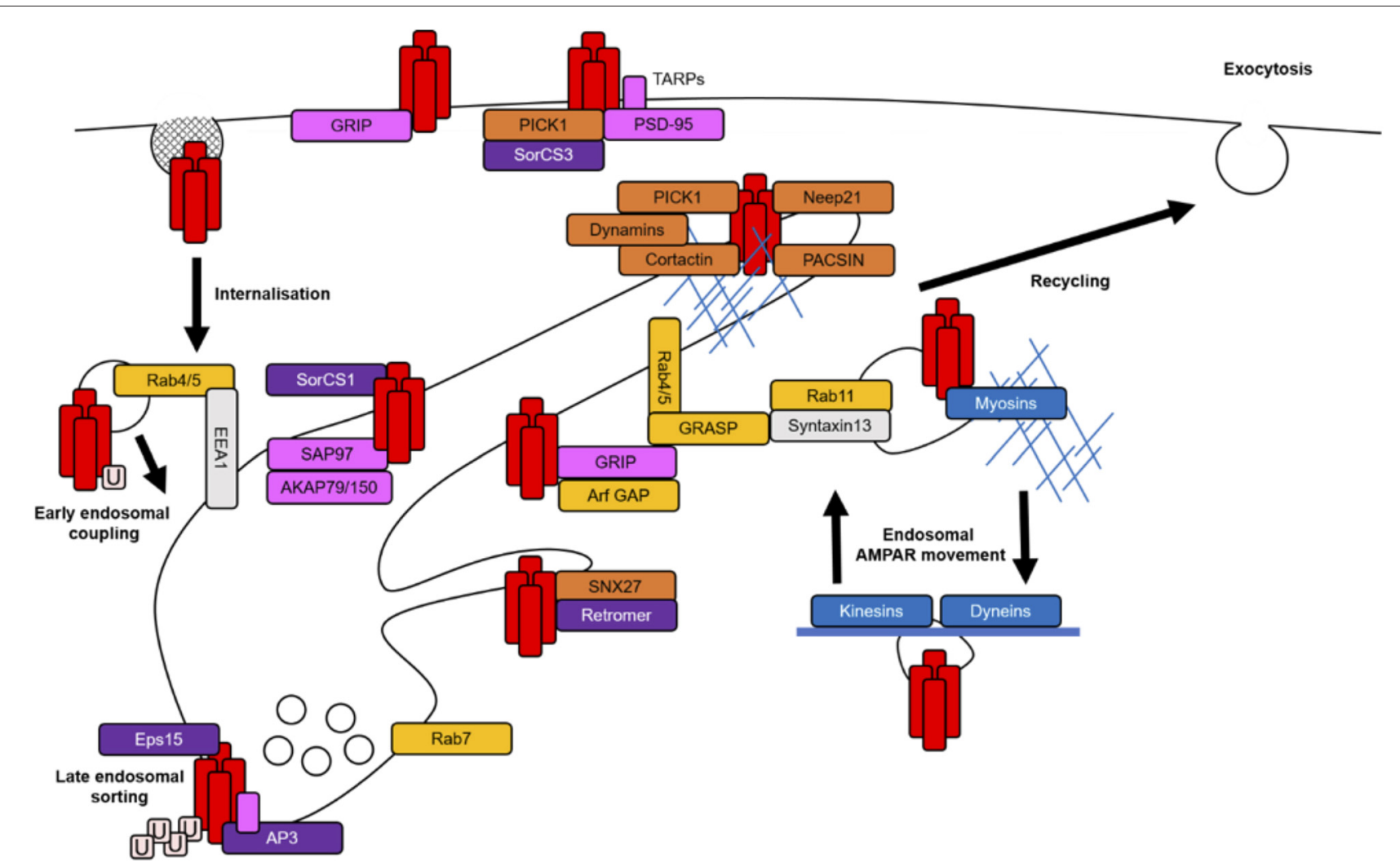

FIGURE 2 | AMPAR-associated proteins in endosomal trafficking routes. AMPARs (red rectangles) are stabilized at the PSD by scaffolding proteins (pink rectangles). AMPARs are internalized largely via clathrin-mediated endocytosis (CME). AMPARs may be tagged for internalization by a single ubiquitin (pale pink squares) and those destined to be degraded are polyubiquitinated. The entry of AMPARs into the early endosomal system is mediated by the tethering protein EE antigen 1 (EEA1) and small GTPases and their effectors (yellow rectangles). The sorting of AMPARs at EEs involves protein complexes that link AMPARs to late or recycling endosomal compartments during coating and initial membrane budding events (purple rectangles). For example, adaptor protein 3 (AP3) and epidermal growth factor receptor substrate 15 (Eps15) in degradative paths and retromer and SorCS1 in recycling paths. The latter stages of AMPAR sorting also require the recruitment of proteins with diverse functions, such as PICK1, sorting nexin 27 (SNX27), protein kinase C and casein kinase II substrate in neurons (PACSIN) and Neep21, which complete the budding process via actin remodeling or generation of membrane curvature and prepare AMPARs for the next stages of their trafficking (orange rectangles). All stages of AMPAR sorting require small GTPase activation for the coordination of protein signaling and recruitment; Rab4/5 for endosomal entry, Rab7 for degradation and Rab11 or Arfs for recycling pathways. The actin cytoskeleton (thin blue lines) is mainly thought to facilitate endosomal transport in dendritic spines when coupled with certain associated proteins (blue rectangles), such as myosins. Microtubules (thick blue line) regulate longer range transport and promote the delivery of AMPARs to distal dendrites.

shown whether disrupting Rab5 function affects only AMPAR internalization or whether vesicle to endosome fusion is also interrupted.

\section{Endosomal Sorting}

From EEs, a highly regulated process is needed to correctly sort AMPARs to the appropriate subsequent trafficking compartments. The sorting of cargo for degradation involves its localization to intraluminal MVB vesicles in the bulbous region of EEs (Babst, 2011). Subsequent sorting into LEs is mediated by ubiquitin interacting motif containing proteins, such as epsins, Hrs and Golgi-localized, gamma ear-containing Arf-binding proteins (GGAs) and the endosomal sorting complexes required for transport I, II, III (ESCRT I, II, III) machinery (Hicke and Dunn, 2003; Piper and Luzio, 2007; Babst, 2011). Until relatively recently, plasma membrane receptor recycling in mammalian cells was thought to be passive and rely heavily on the greater surface area of recycling tubular endosomal compartments to trap cargo for default return to the plasma membrane (Puthenveedu et al., 2010). However, many active sorting mechanisms into recycling pathways are being discovered.

\section{Post-translational Modifications}

Dynamic PTMs such as phosphorylation, palmitoylation and ubiquitination influence AMPAR trafficking via numerous and varied mechanisms (Lu and Roche, 2012). For example, NMDAR-dependent AMPAR internalization during LTD involves GluA1 dephosphorylation at S845 (Lee et al., 1998; Ehlers, 2000), whereas AMPAR recycling during LTP involves GluA1 phosphorylation at S845 and S831 (Oh et al., 2006; He et al., 2009; Lee et al., 2010). On the other hand, phosphorylation of GluA2 subunit is regulated mainly in response to LTD induction to trigger AMPAR internalization (Kim et al., 2001; Ahmadian et al., 2004). While these 
signaling events have primarily been attributed to altering endocytosis rates, GluA1 S845 phosphonull mutants have been shown to degrade more rapidly in lysosomal compartments, instead of recycling back to the plasma membrane ( $\mathrm{He}$ et al., 2009).

The most studied PTM involved in AMPAR sorting to degradative pathways is ubiquitination, which is the covalent addition of a 76 amino acid ubiquitin tag to lysine residues of a targeted protein. Although it is unclear whether AMPAR ubiquitination occurs at the postsynaptic plasma membrane (Patrick et al., 2003; Schwarz et al., 2010), or in EEs (Lussier et al., 2011; Widagdo et al., 2015), these ubiquitination events represent an early sorting event that can target cargo for degradation. All 4 AMPAR subunits can be ubiquitinated; GluA1 at K868 and GluA2 at K870 and K882 (Schwarz et al., 2010; Lussier et al., 2011; Widagdo et al., 2015). Lysine to arginine "ubiquitin-null" mutations at these sites result in reduced degradation and lysosomal targeting of AMPAR subunits (Lin et al., 2011; Widagdo et al., 2015). Moreover, expression of ubiquitin mutants that lack the ability to form polyubiquitin chains also prevent AMPAR internalization (Patrick et al., 2003). However, ubiquitination does not appear to be downstream of NMDAR activation, and so is unlikely to account for AMPAR degradation during LTD (Lussier et al., 2011; Widagdo et al., 2015). E3 ubiquitin ligases are critical for conjugating ubiquitin to substrates, and Nedd4-1 is recruited to synapses to increase ubiquitin-mediated AMPAR degradation following long-term bicuculline treatments $(>20 \mathrm{~h})$ to induce homeostatic downscaling. This homeostatic mechanism is directly antagonized by NMDAR-dependent activation of the deubiquitinating enzyme ubiquitin carboxyl-terminal hydrolase 8 (USP8), to favor AMPAR deubiquitination and therefore AMPAR recycling (Scudder et al., 2014). RNF1 is another E3 ligase that is found at neuronal plasma membranes where it ubiquitinates AMPARs in response to AMPAR stimulation to decrease their surface expression via lysosomal degradation (Lussier et al., 2012).

Mechanistically, PTMs select AMPARs for recycling or degradation by altering their interactions with accessory trafficking proteins, which are discussed in the following sections. However, in the case of some PTMs, relevant regulated protein-protein interactions have not been identified.

\section{Scaffolding Proteins}

Scaffolding proteins contain multiple interaction domains to bring important signaling or trafficking proteins into close proximity to AMPARs. GRIP contains seven PDZ domains that can simultaneously bind different PDZ ligand-containing proteins and maintains AMPAR surface expression via direct interaction with GluA2/3. The precise mechanism is still a matter of debate, and early studies hypothesized that the GRIP-AMPAR interaction functioned to stabilize AMPARs at the synaptic membrane (Dong et al., 1999; Osten et al., 2000), but it was later suggested that GRIP links AMPAR-containing REs to kinesin motor proteins and exocytic proteins to facilitate endosomal recycling back to the plasma membrane (Setou et al., 2002; Mao et al., 2010; Thomas et al., 2012). The GRIP-AMPAR interaction is blocked by phosphorylation of GluA2 at Ser880, which is regulated in response to LTD induction (Chung et al., 2000; Kim et al., 2001; Chung et al., 2003) or synaptic scaling (Tan et al., 2015). Additional mechanistic insight into GRIP function is provided by the observation that NSG1/Neep21, a small transmembrane protein that regulates the recycling of AMPARs in basal neuronal conditions interacts with GRIP. This interaction selectively promotes the return of GluA2-containing AMPARs to the plasma membrane, thereby diverting them from lysosomal degradation (Alberi et al., 2005; Steiner et al., 2005).

SAP97 is a PDZ domain containing scaffolding protein and a member of the membrane-associated guanylate kinase (MAGUK) protein family, which binds directly to GluA1 subunit and is thought to be involved in delivering AMPARs to the plasma membrane from intracellular compartments (Leonard et al., 1998; Schlüter et al., 2006). SAP97 forms a complex with GluA1-containing AMPARs and the actin motor protein myosin VI, which supports a role for SAP97 in AMPAR endocytosis and recycling (Wu et al., 2002; Osterweil et al., 2005; Nash et al., 2010). Although myosin VI is usually associated with cargo transport away from the plasma membrane towards actin minus ends, it should be noted that actin polarity is not uniform in mature dendritic spines and so myosin VI could regulate AMPAR traffic towards or away from the plasma membrane in dendritic spines (Nash et al., 2010). However, controversy remains about whether SAP97 regulates basal and/or activity-dependent AMPAR trafficking during LTP (Nakagawa et al., 2004; Schlüter et al., 2006; Howard et al., 2010). These discrepancies are likely due to the incomplete understanding of SAP97 splice variants in early studies and the functional redundancy within the MAGUK protein family (Howard et al., 2010; Liu et al., 2014).

Membrane-associated guanylate kinase inverted 2 (MAGI2) is structurally related to MAGUKs in that it contains a guanylate kinase-like domain and multiple PDZ domains, and proposed to act as an AMPAR scaffolding protein. MAGI2 interacts with AMPARs via TARPs (Deng et al., 2006), and is thought to maintain an intracellular pool of AMPARs, and hence constitutive AMPAR recycling to the plasma membrane (Danielson et al., 2012a,b).

AKAP79/150 interacts with AMPARs indirectly via SAP97 and contains binding domains for several kinases and phosphatases, such as PKA and calcineurin (Sanderson and Dell'Acqua, 2011). It is essential for anchoring PKA and calcineurin in close proximity to homomeric GluA1 AMPARs, so that they are transiently recruited to the synapse during LTD, LTP and homeostatic plasticity (Lu et al., 2007; Sanderson et al., 2018). AKAP79/150 is a substrate for the palmitoyl acyl transferase DHHC2, which is associated with REs (Greaves and Chamberlain, 2011; Woolfrey et al., 2015). Palmitoylation of AKAP79/150 by DHHC2 is required for AMPAR trafficking to the plasma membrane during LTP, probably as a result of more efficient PKA-dependent GluA1 phosphorylation (Keith et al., 2012; Woolfrey et al., 2015). It has also been suggested that CaMKII may cause the depalmitoylation of AKAP79/150 by an unknown mechanism, resulting in its removal from endosomal 
membranes in spines during LTD (Woolfrey et al., 2018). This may also influence AMPAR trafficking, but has not been empirically tested.

In summary, AMPAR scaffolding proteins contain a variety of protein interaction domains to coordinate complex trafficking processes by clustering AMPARs, auxiliary subunits, kinases and phosphatases onto intracellular membrane compartments and the plasma membrane. The complement of proteins recruited by scaffolding proteins and the consequent signaling events influence how and when the next stage of the trafficking process takes place.

\section{Auxiliary AMPAR Subunits}

The core pore-forming AMPAR subunits associate with several families of transmembrane proteins, often referred to as auxiliary subunits, which alter AMPAR channel properties and trafficking (Sumioka, 2013; Haering et al., 2014; Jacobi and von Engelhardt, 2018). The most studied family of auxiliary subunits are the TARPs, originally identified as calcium channel $\gamma$ subunits (Jackson and Nicoll, 2011; Greger et al., 2017). The prototypical TARP stargazin $/ \gamma 2$ interacts directly with AMPAR subunits to maintain their surface expression and facilitate clustering via PSD95 interactions (Chen et al., 2000; Schnell et al., 2002; Tomita et al., 2005; Bats et al., 2007). Additional AMPAR auxiliary subunits have been identified, for example cysteine-knot AMPAR modulating proteins (CKAMPs), which also influence AMPAR channel activity and regulate AMPAR trafficking through the biosynthetic pathway (Schwenk et al., 2012; Farrow et al., 2015). Since cargo exit from all intracellular membrane compartments are mechanistically similar and AMPAR auxiliary subunits interact with a variety of endosomal trafficking proteins, it is possible that similar mechanisms regulate AMPAR exit from biosynthetic and endosomal compartments. Indeed, TARP $\gamma 2$ has been shown to interact with the adaptor protein (AP) complex AP-3 to promote AMPAR late endosomal/lysosomal trafficking (Matsuda et al., 2013). Moreover, another AMPAR interacting protein, PICK1, which regulates AMPAR trafficking at secretory and endosomal membranes ( $\mathrm{Lu}$ et al., 2014; Mignogna et al., 2015), forms a complex with protein kinase C alpha (PKC $\alpha$ ) and CKAMP44 (Kunde et al., 2017). Thus, it will be interesting to determine how PICK1-recruited PKC $\alpha$-mediated phosphorylation of CKAMP44 alters AMPAR surface expression during synaptic plasticity events and whether it occurs at endosomal compartments.

The study of auxiliary AMPAR subunits is a rapidly evolving area of AMPAR trafficking research. Although much insight has been gained on understanding the ability of TARPs to alter AMPAR trafficking and channel properties, much more work needs to be done to elucidate how the lesser studied AMPAR auxiliary subunits regulate these processes.

\section{Linking Membrane Budding to AMPARs}

The vesicular transport hypothesis states that intracellular trafficking of cargo between intracellular compartments in mammalian cells occurs via the encapsulation of cargo proteins, such as AMPARs, into small vesicles that bud from a donor compartment and fuse with an acceptor compartment (Bonifacino and Glick, 2004). Proteins involved in the early stages of membrane budding at plasma membrane and endosomal compartments form complexes of vesicle coating proteins, such as clathrin, APs and additional accessory proteins to link cargo to the nascent bud and coordinate subsequent trafficking (Lee and Goldberg, 2010).

Endocytosis from the plasma membrane and sorting into LEs often involves protein interactions with regions on the cargo proteins that are rich in lysine and arginine residues (Heo et al., 2006; Yeung et al., 2008), which are present in the cytoplasmic tails of AMPARs. This KR-rich region of AMPARs shows high homology across all its subunits, and is the region on GluA2 that binds the endocytic AP complex AP-2 (Lee et al., 2002). In addition, AMPAR sorting into LEs and subsequent lysosomal degradation in response to LTD induction is mediated by the KR-rich region of GluA2 (Lee et al., 2004). While classical AP complexes for lysosomal sorting (e.g., AP-3) have not been shown to bind to this site, the GluA2 interacting proteins cortactin and NSF play an important role. NSF can disrupt PICK1-GluA2 interactions, and hence regulate lysosomal trafficking of AMPARs (Hanley et al., 2002; Lee et al., 2004; Koszegi et al., 2017). It has recently been shown that the cortactin-AMPAR interaction maintains surface and total levels of GluA2/3-containing AMPAR by facilitating their recycling (Parkinson et al., 2018). NMDAR stimulation disrupts the interaction, resulting in the trafficking of AMPARs to lysosomes and their consequent degradation.

Nevertheless, a mechanism that does involve AP-3 has been identified, whereby the $\mu 3 \mathrm{~A}$ subunit of AP-3 interacts with the C-terminal tail of TARP $\gamma 2$ in a phosphorylation-dependent manner to promote the late endosomal/lysosomal trafficking of AMPARs during NMDAR-dependent LTD (Matsuda et al., 2013). However, a recent study suggests that $\mu 3 \mathrm{~A}$, functioning independently of the AP-3 complex, actually promotes the recycling of AMPARs to the plasma membrane during homeostatic scaling-up (Steinmetz et al., 2016). This mechanism also requires the GluA2-binding scaffolding protein GRIP.

Epidermal growth factor receptor substrate 15 (eps15) is an endocytic accessory protein that binds to AP-2 and contains a ubiquitin interacting motif and three Eps15 homology $(\mathrm{EH})$ domains, which are widely present in endocytic accessory proteins (Benmerah et al., 1998; Confalonieri and Di Fiore, 2002). Eps15 has been shown to bind to ubiquitinated GluA1-containing AMPARs, facilitate their clathrin-dependent internalization and subsequent trafficking to lysosomes following neuronal stimulation (Lin and Man, 2014).

Sorting receptors are transmembrane proteins that couple cargo proteins to vesicle coats at the endoplasmic reticulum for efficient transport to the Golgi (Dancourt and Barlowe, 2010). The sorting receptor SorCS1, localizes to neuronal EEs and REs, interacts with AMPARs and regulates their basal surface expression (Savas et al., 2015). A related sorting receptor, SorCS3, interacts with PSD95 and PICK1 and has been proposed to promote synaptic efficacy through retaining surface AMPAR expression (Christiansen et al., 2017). 
Retromer is a heteromeric complex of 5 proteins that was originally identified as a crucial mediator of retrograde trafficking, but is now emerging as an important regulator of recycling and lysosomal pathways (Burd and Cullen, 2014). It is a large complex comprising vacuolar protein sorting (VPS) proteins that constitute the "cargo selective complex," which recognize and bind to cargo, and sorting nexins (SNXs), which link the cargo to the budding vesicle. AMPARs have recently been shown to utilize the retromer complex for local delivery from dendritic endosomes to synapses during basal trafficking (Choy et al., 2014; Tian et al., 2015) and activitydependent trafficking in response to LTP induction (Temkin et al., 2017). SNXs contain a PX domain that interacts primarily with PI(3)P lipids, which are typically present on endosomal compartments (Gillooly et al., 2000; Teasdale and Collins, 2012). SNX27 also contains a PDZ domain and associates with GluA1 to promote AMPAR recycling during LTP and under basal conditions (Hussain et al., 2014; Loo et al., 2014).

The proteins described in this section link the clustered and primed native AMPAR complexes to particular trafficking membranes via coating, adaptor and accessory proteins that begin the membrane deformation process. Although some studies have identified proteins that sort AMPARs into recycling tubules or late endosomal compartments, most of the known machinery that regulates mammalian receptor sorting, for example ESCRT proteins, coat protein complex (COP) I and II, and other APs such as AP-4 and AP-5, have yet to be investigated in the specific context of AMPAR trafficking.

\section{Membrane Lipid Composition and Curvature}

Endosomal membranes exhibit varying degrees of curvature and are marked by a unique complement of lipids, the most defining of which are the phosphoinositides (Ueda, 2014). AMPAR-associated proteins that differentially recognize phospholipids can target AMPARs to specific membranes and thus play crucial roles in coordinating the molecular events at the intersection between one membrane and the next. Furthermore, the regulation of phosphoinositide membrane identity via lipid de/phosphorylation is an important aspect of AMPAR trafficking. For example, the phosphoinositide-3-kinase (PI3K)-mediated phosphorylation of phosphatidylinositol 4,5-bisphosphate $\left(\mathrm{PI}(4,5) \mathrm{P}_{2}\right)$ to phosphatidylinositol (3,4,5)-trisphosphate $\left(\mathrm{PIP}_{3}\right)$ and its reciprocal dephosphorylation by PTEN regulate the local accumulation of $\mathrm{PIP}_{3}$ at AMPAR-containing intracellular membrane compartments. Homotypic fusion of these intracellular AMPAR pools and $\mathrm{PIP}_{3}$-rich plasma membrane domains result in AMPAR synaptic insertion during LTP (Man et al., 2003; Arendt et al., 2010; Moult et al., 2010; Chan et al., 2011). Conversely, PTEN activity has been shown to depress AMPA receptor-mediated synaptic transmission and is required for NMDAR-dependent LTD, which is consistent with a loss of $\mathrm{PIP}_{3}$-containing plasma membrane identity to promote AMPAR synaptic removal (Jurado et al.,
2010). $\mathrm{PI}(4,5) \mathrm{P}_{2}$ is enriched at the plasma membrane and at intracellular membranes often associated with degradative pathways (Tan et al., 2015). The lipid phosphatase synaptojanin dephosphorylates $\mathrm{PI}(4,5) \mathrm{P}_{2}$, so that endocytic vesicles can lose their plasma membrane identity, uncoat and traffic to the next intracellular compartment (Cremona et al., 1999). Although synaptojanin activity is required for AMPAR endocytosis (Gong and De Camilli, 2008), more recent work suggests that synaptojanin could also regulate the sorting of receptors at endosomal compartments. These studies demonstrate that disrupting synaptojanin function results in an intracellular accumulation of endosomal structures, suggesting that synaptojanin facilitates the maturation of endocytic vesicle membrane identity to allow the correct onward trafficking of cargo (Cossec et al., 2012; George et al., 2014).

$\mathrm{PIP}_{3}$ in endosomal membranes may also be phosphorylated by PIKfyve to generate $\mathrm{PI}(3,5) \mathrm{P}_{2}$, which is thought to facilitate basal Rab11-mediated AMPAR synaptic delivery (Seebohm et al., 2012). However, PIKfyve has also been shown to drive synaptic depression by phosphorylating PI(3)P at plasma membranes to generate a more endosomal $\mathrm{PI}(3,5) \mathrm{P}_{2}$ identity and induce AMPAR internalization (Zhang et al., 2012; McCartney et al., 2014). MTMR2 is a 3-phosphatase specific for the phosphoinositides $\mathrm{PI}(3) \mathrm{P}$ and $\mathrm{PI}(3,5) \mathrm{P}_{2}$ (Nicot and Laporte, 2008) and in neurons, acute knockdown of this phosphatase has been shown to enhance GluA2 trafficking to lysosomal compartments (Lee et al., 2010). This is proposed to occur through MTMR2-PSD95 interactions, which localize MTMR2 to excitatory synapses, where it prevents endosomal entry and subsequent lysosomal degradation.

PICK1 contains a BAR domain and a PDZ domain and regulates AMPAR trafficking during basal conditions and in response to LTD induction (Terashima et al., 2004; Steinberg et al., 2006; Terashima et al., 2008). PICK1 binds directly to GluA2, and is involved in AMPAR endocytosis (Fiuza et al., 2017) and endosomal sorting. At endosomal membranes, PICK1 restricts AMPAR recycling to the plasma membrane and may be involved in trafficking to lysosomes (Lin and Huganir, 2007; Citri et al., 2010; Koszegi et al., 2017). It has been suggested that the PICK1 BAR domain preferentially binds mono-phosphoinositides typically associated with endosomal compartments (Jin et al., 2006; Ueda, 2014), while the PDZ domain associates with a number of phospholipids, including PI(4,5) $\mathrm{P}_{2}$ (Pan et al., 2007).

Another BAR-domain containing protein that has been implicated in AMPAR trafficking is PKC and casein kinase II substrate in neurons (PACSIN, also known as Syndapin), which forms a complex with PICK1 and AMPARs to facilitate the activity-dependent internalization of AMPARs for the expression of cerebellar LTD (Anggono et al., 2013). More detailed investigation into the role of PACSIN1 in AMPAR trafficking suggested that PACSIN plays dual roles in AMPAR trafficking; the PICK1-PACSIN1 interaction is essential in activity-dependent recycling of AMPARs, and the $\mathrm{SH} 3$ and F-BAR interactions of PACSIN1 with as yet unidentified partners are important in AMPAR endocytosis (Widagdo et al., 2016). 


\section{AMPAR ENDOSOMAL SORTING IN DISEASE}

There is significant overlap between endo-lysosomal, autophagosomal and ubiquitin-mediated degradation (Korolchuk et al., 2010; Cohen-Kaplan et al., 2016) and the dysregulation of these systems has been consistently observed in neurodegenerative diseases (Nedelsky et al., 2008; Lee et al., 2013). Indeed, endosomal dysfunction is an early indicator for a number of neurodegenerative diseases, such as Alzheimer's disease (AD) and Parkinson's disease (PD; Schreij et al., 2016), Niemann-Pick type C1 (D'Arcangelo et al., 2011; Rabenstein et al., 2017), and other neuropathologies, such as ischemia (Yuan et al., 2018). Crucially, these endosomal deficits result in aberrant lysosomal targeting of crucial synaptic proteins, such as AMPARs, and is thought to underlie the impairments in learning and memory seen in these pathologies. Thus, strategies that promote correct endo/lysosomal fusion, maturation and trafficking of AMPARs are gaining momentum as viable clinical targets in neuropathologies that exhibit endosomal dysfunction (Friedman et al., 2015; Wen et al., 2017). Furthermore, the distinct spatio-temporal differences in the auxiliary subunit composition of native AMPAR complexes throughout the brain (Schwenk et al., 2014), shows promise for the development of targeted therapies for various neuropathologies. Indeed, studies are beginning to develop drugs that preferentially target AMPAR complexes that include specific auxiliary subunits such as stargazin (Azumaya et al., 2017).

Brain ischemia occurs when the blood supply to the brain is interrupted via stroke or cardiac arrest, which causes neuronal depolarization, excessive glutamate release, AMPAR overexcitation and a sustained raise in intracellular $\mathrm{Ca}^{2+}$ (Arundine and Tymianski, 2004). This excitotoxic $\mathrm{Ca}^{2+}$ signaling is caused in part by a reduction in synaptic GluA2-containing AMPARs, and the subsequent expression of GluA2-lacking $\mathrm{Ca}^{2+}$-permeable AMPARs at synapses. This switch is a multistage process involving GluA2-dependent endocytosis from the plasma membrane, and also the aberrant trafficking of GluA2containing AMPARs to lysosomes, where they are degraded (Liu et al., 2006; Blanco-Suarez and Hanley, 2014; Koszegi et al., 2017). A persistent reduction in GluA2 expression after ischemia is maintained by a reduction in mRNA levels by regulation at the level of transcription (Pellegrini-Giampietro et al., 1992; Gorter et al., 1997). The ectopic presence of autolysosomes is increasingly observed from $1 \mathrm{~h}$ to $12 \mathrm{~h}$ after permanent middle cerebral artery occlusion (experimental stroke; Wen et al., 2008). Therefore, clearing ectopic lysosomes and preventing improper degradation of GluA2-containing AMPARs have potential as therapeutic strategies for brain ischemia.

$\mathrm{AD}$ is characterized by an abnormal intracellular accumulation of neurofibrillary tangles of hyper-phosphorylated tau (Iqbal and Grundke-Iqbal, 2008) and extracellular amyloid- $\beta$ ( $A \beta$ ) plaques (Selkoe and Hardy, 2016). In the early stages of AD pathology, Rab5 and Rab7 are upregulated (Ginsberg et al., 2010), which is proposed to precede and exacerbate the accumulation of $\mathrm{A} \beta$ protein aggregates (Takahashi et al., 2002, 2004; Capetillo-Zarate et al., 2011).
Moreover, $\mathrm{A} \beta 42$, the amyloid peptide that is most prone to aggregation, accumulates in LEs and impairs endosomal sorting of neuronal cargo to be degraded, since they cannot translocate from the outer membrane to the inner membrane of MVBs in LEs (Cataldo et al., 2000, 2003; Almeida et al., 2006; Burns and Rebeck, 2010; Jiang et al., 2010; Choi et al., 2013). Impaired endosomal sorting is thought to decrease the surface expression of AMPARs and cause the cognitive defects seen in AD (Almeida et al., 2005; Chang et al., 2006; Hsieh et al., 2006; Ting et al., 2007). The detailed molecular mechanisms of this AMPAR loss remain elusive, but a recent study has shown that $A \beta$ increases Nedd4-1-mediated AMPAR ubiquitination, and knockdown of Nedd4-1 can rescue $A \beta$-induced synaptic deficits (Alfonso et al., 2014; Rodrigues et al., 2016). The aberrant presence of GluA2-lacking, CP-AMPARs, which promotes excessive calcium signaling (LaFerla, 2002; O'Hare Doig et al., 2016) may hyper-phosphorylate tau and augment the formation of toxic A $\beta$ oligomers (Mattson et al., 1993; Pierrot et al., 2006). Interestingly, $A \beta$ selectively decreases GluA2-containing AMPARs through PKC-phosphorylation of serine 880 (Liu et al., 2010; Guntupalli et al., 2016) and causes a rapid synaptic insertion of CP-AMPARs (Whitcomb et al., 2015). Furthermore, GluA3 subunits are most readily associated with GluA2 subunits in the mature hippocampus (Wenthold et al., 1996; Lu et al., 2009) and mice lacking GluA3-containing AMPARs are protected against $A \beta$-induced synaptic deficits, spine loss and memory impairment (Reinders et al., 2016). Therefore, it may be the case that GluA3 subunits are predominantly responsible for AMPAR lysosomal sorting, which is supported by earlier studies (Lee et al., 2004). Preventing GluA2-containing AMPAR lysosomal sorting may hold potential for therapeutic intervention in $\mathrm{AD}$, and targeting GluA3 could be an effective approach to prevent further loss of synaptic GluA2/3 heteromers.

Intraneuronal proteinaceous inclusions, termed Lewy bodies (LBs) that are enriched in $\alpha$-synuclein are observed in PD (Dickson, 2012). Similar to the etiology of AD, these $\alpha$-synuclein aggregations are thought to disrupt intracellular trafficking pathways at late endosomal and lysosomal compartments (Outeiro and Lindquist, 2003; Mazzulli et al., 2011; Volpicelli-Daley et al., 2014). Indeed, $\alpha$-synuclein-induced disruption of the ESCRT-III complex results in decreased MVB formation, intracellular $\alpha$-synuclein aggregation and its consequent exocytosis, which propagates the toxic effects to other neighboring cells (Spencer et al., 2015). Again, enhancing late endosomal function through Rab7 activation has been shown to clear pathological $\alpha$-synuclein aggregates (Dinter et al., 2016), and AMPARs have been identified as important dysregulated trafficking cargo. For example, neurons expressing genetic mutations that are present in familial PD significantly reduce AMPAR surface expression (Cortese et al., 2016). Moreover, retromer dysfunction has also been heavily implicated in the improper trafficking of AMPARs from endosomes to the plasma membrane in $\mathrm{AD}$ (Muhammad et al., 2008; Lane et al., 2012), PD (Munsie et al., 2015) and other neurodegenerative conditions (Damseh et al., 2015). Moreover, extracellular $\alpha$-synuclein increases 
synaptic CP-AMPAR expression (Diógenes et al., 2012) and so targeting GluA2-containing AMPARs and their strict control of intracellular $\mathrm{Ca}^{2+}$ is again of significant clinical importance.

\section{CONCLUDING REMARKS}

The process of endosomal sorting is extremely complex, especially in the context of the extended and polarized morphology of central neurons. Moreover, the system needs to be highly dynamic and respond to different types of synaptic stimulation, and to respond in a local, synapse-specific manner to change the receptor complement of individual synapses. Despite this complexity, significant progress has been made in elucidating the relevant mechanisms. An additional challenge is the interconnected nature of endosomal and vesicular

\section{REFERENCES}

Ahmadian, G., Ju, W., Liu, L., Wyszynski, M., Lee, S. H., Dunah, A. W., et al. (2004). Tyrosine phosphorylation of GluR2 is required for insulin-stimulated AMPA receptor endocytosis and LTD. EMBO J. 23, 1040-1050. doi: 10.1038/sj. emboj.7600126

Alberi, S., Boda, B., Steiner, P., Nikonenko, I., Hirling, H., and Muller, D. (2005). The endosomal protein NEEP21 regulates AMPA receptor-mediated synaptic transmission and plasticity in the hippocampus. Mol. Cell. Neurosci. 29, 313-319. doi: 10.1016/j.mcn.2005.03.011

Alfonso, S., Kessels, H. W., Banos, C. C., Chan, T. R., Lin, E. T., Kumaravel, G., et al. (2014). Synapto-depressive effects of amyloid $\beta$ require PICK1. Eur. J. Neurosci. 39, 1225-1233. doi: 10.1111/ejn.12499

Almeida, C. G., Tampellini, D., Takahashi, R. H., Greengard, P., Lin, M. T., Snyder, E. M., et al. (2005). $\beta$-amyloid accumulation in APP mutant neurons reduces PSD-95 and GluR1 in synapses. Neurobiol. Dis. 20, 187-198. doi: 10.1016/j.nbd.2005.02.008

Almeida, C. G., Takahashi, R. H., and Gouras, G. K. (2006). $\beta$-amyloid accumulation impairs multivesicular body sorting by inhibiting the ubiquitinproteasome system. J. Neurosci. 26, 4277-4288. doi: 10.1523/jneurosci.507805.2006

Anggono, V., and Huganir, R. L. (2012). Regulation of AMPA receptor trafficking and synaptic plasticity. Curr. Opin. Neurobiol. 22, 461-469. doi: 10.1016/j.conb. 2011.12.006

Anggono, V., Koc-Schmitz, Y., Widagdo, J., Kormann, J., Quan, A., Chen, C. M., et al. (2013). PICK1 interacts with PACSIN to regulate AMPA receptor internalization and cerebellar long-term depression. Proc. Natl. Acad. Sci. U S A 110, 13976-13981. doi: 10.1073/pnas.1312467110

Arendt, K. L., Royo, M., Fernández-Monreal, M., Knafo, S., Petrok, C. N., Martens, J. R., et al. (2010). PIP3 controls synaptic function by maintaining AMPA receptor clustering at the postsynaptic membrane. Nat. Neurosci. 13, 36-44. doi: 10.1038/nn.2462

Arundine, M., and Tymianski, M. (2004). Molecular mechanisms of glutamatedependent neurodegeneration in ischemia and traumatic brain injury. Cell. Mol. Life Sci. 61, 657-668. doi: 10.1007/s00018-003-3319-x

Ashby, M. C., De La Rue, S. A., Ralph, G. S., Uney, J., Collingridge, G. L., and Henley, J. M. (2004). Removal of AMPA receptors (AMPARs) from synapses is preceded by transient endocytosis of extrasynaptic AMPARs. J. Neurosci. 24, 5172-5176. doi: 10.1523/jneurosci.1042-04.2004

Azumaya, C. M., Days, E. L., Vinson, P. N., Stauffer, S., Sulikowski, G., Weaver, C. D., et al. (2017). Screening for AMPA receptor auxiliary subunit specific modulators. PLoS One 12:e0174742. doi: 10.1371/journal.pone.01 74742

Babst, M. (2011). MVB vesicle formation: ESCRT-dependent, ESCRTindependent and everything in between. Curr. Opin. Cell Biol. 23, 452-457. doi: 10.1016/j.ceb.2011.04.008 membranes, which leads to experimental difficulties in precisely defining roles for regulatory proteins at specific intracellular compartments. However, future work employing more spatially resolved imaging techniques and better targeted molecular tools in neuronal systems will more completely define the roles of AMPAR trafficking proteins in endosomal sorting.

\section{AUTHOR CONTRIBUTIONS}

GP wrote the original draft of the manuscript. JH edited the manuscript and completed the final version.

\section{FUNDING}

This work was funded by BBSRC grant BB/L007266/1 and a BBSRC SWBio DTP PhD studentship.

Bats, C., Groc, L., and Choquet, D. (2007). The interaction between stargazin and PSD-95 regulates AMPA receptor surface trafficking. Neuron 53, 719-734. doi: 10.1016/j.neuron.2007.01.030

Benmerah, A., Lamaze, C., Bègue, B., Schmid, S. L., Dautry-Varsat, A., and Cerf-Bensussan, N. (1998). Ap-2/Eps15 interaction is required for receptormediated endocytosis. J. Cell Biol. 140, 1055-1062. doi: 10.1083/jcb.140.5.1055

Blanco-Suarez, E., and Hanley, J. G. (2014). Distinct subunit-specific $\alpha$-amino3-hydroxy-5-methyl-4-isoxazolepropionic acid (AMPA) receptor trafficking mechanisms in cultured cortical and hippocampal neurons in response to oxygen and glucose deprivation. J. Biol. Chem. 289, 4644-4651. doi: $10.1074 /$ jbc.M113.533182

Bonifacino, J. S., and Glick, B. S. (2004). The mechanisms of vesicle budding and fusion. Cell 116, 153-166. doi: 10.1016/s0092-8674(03)01079-1

Bredt, D., and Nicholl, R. A. (2003). AMPA receptor trafficking at excitatory synapses. Neuron 40, 361-379. doi: 10.1016/s0896-6273(03)00640-8

Brown, T. C., Tran, I. C., Backos, D. S., and Esteban, J. A. (2005). NMDA receptordependent activation of the small GTPase Rab5 drives the removal of synaptic AMPA receptors during hippocampal LTD. Neuron 45, 81-94. doi: 10.1016/j. neuron.2004.12.023

Burd, C., and Cullen, P. J. (2014). Retromer: a master conductor of endosome sorting. Cold Spring Harb. Perspect. Biol. 6:a016774. doi: 10.1101/cshperspect. a016774

Burns, M. P., and Rebeck, G. W. (2010). Intracellular cholesterol homeostasis and amyloid precursor protein processing. Biochim. Biophys. Acta 1801, 853-859. doi: 10.1016/j.bbalip.2010.03.004

Capetillo-Zarate, E., Gracia, L., Yu, F., Banfelder, J. R., Lin, M. T., Tampellini, D., et al. (2011). High-resolution 3D reconstruction reveals intra-synaptic amyloid fibrils. Am. J. Pathol. 179, 2551-2558. doi: 10.1016/j.ajpath.2011.07.045

Cataldo, A. M., Petanceska, S., Peterhoff, C. M., Terio, N. B., Epstein, C. J., Villar, A., et al. (2003). App gene dosage modulates endosomal abnormalities of Alzheimer's disease in a segmental trisomy 16 mouse model of down syndrome. J. Neurosci. 23, 6788-6792. doi: 10.1523/jneurosci.23-17-06788.2003

Cataldo, A. M., Peterhoff, C. M., Troncoso, J. C., Gomez-Isla, T., Hyman, B. T., and Nixon, R. A. (2000). Endocytic pathway abnormalities precede amyloid $\beta$ deposition in sporadic Alzheimer's disease and down syndrome: differential effects of APOE genotype and presenilin mutations. Am. J. Pathol. 157, 277-286. doi: 10.1016/s0002-9440(10)64538-5

Chan, C. B., Chen, Y., Liu, X., Tang, X., Lee, C. W., Mei, L., et al. (2011). PIKEmediated PI3-kinase activity is required for AMPA receptor surface expression. EMBO J. 30, 4274-4286. doi: 10.1038/emboj.2011.281

Chang, E. H., Savage, M. J., Flood, D. G., Thomas, J. M., Levy, R. B., Mahadomrongkul, V., et al. (2006). AMPA receptor downscaling at the onset of Alzheimer's disease pathology in double knockin mice. Proc. Natl. Acad. Sci. U S A 103, 3410-3415. doi: 10.1073/pnas.0507313103

Chen, L., Chetkovich, D. M., Petralia, R. S., Sweeney, N. T., Kawasaki, Y., Wenthold, R. J., et al. (2000). Stargazin regulates synaptic targeting of AMPA 
receptors by two distinct mechanisms. Nature 408, 936-943. doi: 10.1038/ 35050030

Choi, Y. J., Chae, S., Kim, J. H., Barald, K. F., Park, J. Y., and Lee, S. H. (2013). Neurotoxic amyloid $\beta$ oligomeric assemblies recreated in microfluidic platform with interstitial level of slow flow. Sci. Rep. 3:1921. doi: 10.1038/srep 01921

Choy, R. W. Y., Park, M., Temkin, P., Herring, B. E., Marley, A., Nicoll, R. A., et al. (2014). Retromer mediates a discrete route of local membrane delivery to dendrites. Neuron 82, 55-62. doi: 10.1016/j.neuron.2014.02.018

Christiansen, G. B., Andersen, K. H., Riis, S., Nykjaer, A., Bolcho, U., Jensen, M. S., et al. (2017). The sorting receptor SorCS3 is a stronger regulator of glutamate receptor functions compared to GABAergic mechanisms in the hippocampus. Hippocampus 27, 235-248. doi: 10.1002/hipo.22689

Chung, H. J., Steinberg, J. P., Huganir, R. L., and Linden, D. J. (2003). Requirement of AMPA receptor GluR2 phosphorylation for cerebellar long-term depression. Science 300, 1751-1755. doi: 10.1126/science.1082915

Chung, H. J., Xia, J., Scannevin, R. H., Zhang, X., and Huganir, R. L. (2000). Phosphorylation of the AMPA receptor subunit GluR2 differentially regulates its interaction with PDZ domain-containing proteins. J. Neurosci. 20, 7258-7267. doi: 10.1523/jneurosci.20-19-07258.2000

Citri, A., Bhattacharyya, S., Ma, C., Morishita, W., Fang, S., Rizo, J., et al. (2010). Calcium binding to PICK1 is essential for the intracellular retention of AMPA receptors underlying long-term depression. J. Neurosci. 30, 16437-16452. doi: 10.1523/jneurosci.4478-10.2010

Cohen-Kaplan, V., Livneh, I., Avni, N., Cohen-Rosenzweig, C., and Ciechanover, A. (2016). The ubiquitin-proteasome system and autophagy: coordinated and independent activities. Int. J. Biochem. Cell Biol. 79, 403-418. doi: 10.1016/j.biocel.2016.07.019

Collinet, C., Stöter, M., Bradshaw, C. R., Samusik, N., Rink, J. C., Kenski, D., et al. (2010). Systems survey of endocytosis by multiparametric image analysis. Nature 464, 243-249. doi: 10.1038/nature08779

Collingridge, G. L., Peineau, S., Howland, J. G., and Wang, Y. T. (2010). Long-term depression in the CNS. Nat. Rev. Neurosci. 11, 459-473. doi: 10.1038/nrn2867

Confalonieri, S., and Di Fiore, P. P. (2002). The Eps15 homology (EH) domain. FEBS Lett. 513, 24-29. doi: 10.1016/s0014-5793(01)03241-0

Cooney, J. R., Hurlburt, J. L., Selig, D. K., Harris, K. M., and Fiala, J. C. (2002). Endosomal compartments serve multiple hippocampal dendritic spines from a widespread rather than a local store of recycling membrane. J. Neurosci. 22, 2215-2224. doi: 10.1523/jneurosci.22-06-02215.2002

Cortese, G. P., Zhu, M., Williams, D., Heath, S., and Waites, C. L. (2016). Parkin deficiency reduces hippocampal glutamatergic neurotransmission by impairing AMPA receptor endocytosis. J. Neurosci. 36, 12243-12258. doi: 10.1523/jneurosci.1473-16.2016

Cosker, K. E., and Segal, R. A. (2014). Neuronal signaling through endocytosis. Cold Spring Harb. Perspect. Biol. 6:a020669. doi: 10.1101/cshperspect.a020669

Cossec, J. C., Lavaur, J., Berman, D. E., Rivals, I., Hoischen, A., Stora, S., et al. (2012). Trisomy for synaptojanin1 in down syndrome is functionally linked to the enlargement of early endosomes. Hum. Mol. Genet. 21, 3156-3172. doi: $10.1093 / \mathrm{hmg} / \mathrm{dds} 142$

Cremona, O., Di Paolo, G., Wenk, M. R., Lüthi, A., Kim, W. T., Takei, K., et al. (1999). Essential role of phosphoinositide metabolism in synaptic vesicle recycling. Cell 99, 179-188. doi: 10.1016/s0092-8674(00)81649-9

D’Arcangelo, G., Grossi, D., De Chiara, G., De Stefano, M. C., Cortese, G., Citro, G., et al. (2011). Glutamatergic neurotransmission in a mouse model of Niemann-Pick Type C disease. Brain Res. 1396, 11-19. doi: 10.1016/j.brainres. 2011.04.020

Damseh, N., Danson, C. M., Al-Ashhab, M., Abu-Libdeh, B., Gallon, M., Sharma, K., et al. (2015). A defect in the retromer accessory protein, SNX27, manifests by infantile myoclonic epilepsy and neurodegeneration. Neurogenetics 16, 215-221. doi: 10.1007/s10048-015-0446-0

Dancourt, J., and Barlowe, C. (2010). Protein sorting receptors in the early secretory pathway. Annu. Rev. Biochem. 79, 777-802. doi: 10.1146/annurevbiochem-061608-091319

Danielson, E., Metallo, J., and Lee, S. H. (2012a). Role of TARP interaction in S-SCAM-mediated regulation of AMPA receptors. Channels 6, 393-397. doi: $10.4161 /$ chan. 21301

Danielson, E., Zhang, N., Metallo, J., Kaleka, K., Shin, S. M., Gerges, N., et al. (2012b). S-SCAM/MAGI-2 is an essential synaptic scaffolding molecule for the GluA2-containing maintenance pool of AMPA receptors. J. Neurosci. 32, 6967-6980. doi: 10.1523/JNEUROSCI.0025-12.2012

Deng, F., Price, M. G., Davis, C. F., Mori, M., and Burgess, D. L. (2006). Stargazin and other transmembrane AMPA receptor regulating proteins interact with synaptic scaffolding protein MAGI-2 in brain. J. Neurosci. 26, 7875-7884. doi: 10.1523/jneurosci.1851-06.2006

Dickson, D. W. (2012). Parkinson's disease and parkinsonism: neuropathology. Cold Spring Harb. Perspect. Med. 2:a009258. doi: 10.1101/cshperspect.a0 09258

Dinter, E., Saridaki, T., Nippold, M., Plum, S., Diederichs, L., Komnig, D., et al. (2016). Rab7 induces clearance of $\alpha$-synuclein aggregates. J. Neurochem. 138, 758-774. doi: 10.1111/jnc.13712

Diógenes, M. J., Dias, R. B., Rombo, D. M., Vicente Miranda, H., Maiolino, F., Guerreiro, P., et al. (2012). Extracellular $\alpha$-synuclein oligomers modulate synaptic transmission and impair LTP via NMDA-receptor activation. J. Neurosci. 32, 11750-11762. doi: 10.1523/jneurosci.0234-12.2012

Dong, H., Zhang, P., Song, I., Petralia, R. S., Liao, D., and Huganir, R. L. (1999). Characterization of the glutamate receptor-interacting proteins GRIP1 and GRIP2. J. Neurosci. 19, 6930-6941. doi: 10.1523/jneurosci.19-16-06930.1999

Ehlers, M. D. (2000). Reinsertion or degradation of AMPA receptors determined by activity-dependent endocytic sorting. Neuron 28, 511-525. doi: 10.1016/s0896-6273(00)00129-x

Esteves da Silva, M., Adrian, M., Schätzle, P., Lipka, J., Watanabe, T., Cho, S., et al. (2015). Positioning of AMPA receptor-containing endosomes regulates synapse architecture. Cell Rep. 13, 933-943. doi: 10.1016/j.celrep.2015. 09.062

Farrow, P., Khodosevich, K., Sapir, Y., Schulmann, A., Aslam, M., Stern-Bach, Y., et al. (2015). Auxiliary subunits of the CKAMP family differentially modulate AMPA receptor properties. Elife 4:e09693. doi: 10.7554/eLife.09693

Fernandes, D., and Carvalho, A. L. (2016). Mechanisms of homeostatic plasticity in the excitatory synapse. J. Neurochem. 139, 973-996. doi: 10.1111/jnc.13687

Fernández-Monreal, M., Brown, T. C., Royo, M., and Esteban, J. A. (2012). The balance between receptor recycling and trafficking toward lysosomes determines synaptic strength during long-term depression. J. Neurosci. 32, 13200-13205. doi: 10.1523/jneurosci.0061-12.2012

Fiuza, M., Rostosky, C. M., Parkinson, G. T., Bygrave, A. M., Halemani, N., Baptista, M., et al. (2017). PICK1 regulates AMPA receptor endocytosis via direct interactions with AP2 $\alpha$-appendage and dynamin. J. Cell Biol. 216, 3323-3338. doi: 10.1083/jcb.201701034

Friedman, L. G., Qureshi, Y. H., and Yu, W. H. (2015). Promoting autophagic clearance: viable therapeutic targets in Alzheimer's disease. Neurotherapeutics 12, 94-108. doi: 10.1007/s13311-014-0320-z

Fujii, S., Tanaka, H., and Hirano, T. (2017). Detection and characterization of individual endocytosis of AMPA-type glutamate receptor around postsynaptic membrane. Genes Cells 22, 583-590. doi: 10.1111/gtc.12493

Gaullier, J. M., Ronning, E., Gillooly, D. J., and Stenmark, H. (2000). Interaction of the EEA1 FYVE finger with phosphatidylinositol 3-phosphate and early endosomes. Role of conserved residues. J. Biol. Chem. 275, 24595-24600. doi: 10.1074/jbc.m906554199

George, A. A., Hayden, S., Holzhausen, L. C., Ma, E. Y., Suzuki, S. C., and Brockerhoff, S. E. (2014). Synaptojanin 1 is required for endolysosomal trafficking of synaptic proteins in cone photoreceptor inner segments. PLoS One 9:e84394. doi: 10.1371/journal.pone.0084394

Gillooly, D. J., Morrow, I. C., Lindsay, M., Gould, R., Bryant, N. J., Gaullier, J. M., et al. (2000). Localization of phosphatidylinositol 3-phosphate in yeast and mammalian cells. EMBO J. 19, 4577-4588. doi: 10.1093/emboj/19.17.4577

Ginsberg, S. D., Alldred, M. J., Counts, S. E., Cataldo, A. M., Neve, R. L., Jiang, Y., et al. (2010). Microarray analysis of hippocampal CA1 neurons implicates early endosomal dysfunction during Alzheimer's disease progression. Biol. Psychiatry 68, 885-893. doi: 10.1016/j.biopsych.2010.05.030

Glebov, O. O., Tigaret, C. M., Mellor, J. R., and Henley, J. M. (2015). Clathrinindependent trafficking of AMPA receptors. J. Neurosci. 35, 4830-4836. doi: 10.1523/jneurosci.3571-14.2015

Gong, L.-W., and De Camilli, P. (2008). Regulation of postsynaptic AMPA responses by synaptojanin 1. Proc. Natl. Acad. Sci. U S A 105, 17561-17566. doi: 10.1073/pnas.0809221105

Goo, M. S., Sancho, L., Slepak, N., Boassa, D., Deerinck, T. J., Ellisman, M. H., et al. (2017). Activity-dependent trafficking of lysosomes in dendrites 
and dendritic spines. J. Cell Biol. 216, 2499-2513. doi: 10.1083/jcb.2017 04068

Gorter, J. A., Petrozzino, J. J., Aronica, E. M., Rosenbaum, D. M., Opitz, T., Bennett, M. V., et al. (1997). Global ischemia induces downregulation of Glur2 mRNA and increases AMPA receptor-mediated $\mathrm{Ca}^{2+}$ influx in hippocampal CA1 neurons of gerbil. J. Neurosci. 17, 6179-6188. doi: 10.1523/jneurosci.17-16-06179.1997

Greaves, J., and Chamberlain, L. H. (2011). DHHC palmitoyl transferases: substrate interactions and (patho)physiology. Trends Biochem. Sci. 36, 245-253. doi: 10.1016/j.tibs.2011.01.003

Greger, I. H., Khatri, L., Kong, X., and Ziff, E. B. (2003). AMPA receptor tetramerization is mediated by $\mathrm{Q} / \mathrm{R}$ editing. Neuron 40, 763-774. doi: 10.1016/s0896-6273(03)00668-8

Greger, I. H., Watson, J. F., and Cull-Candy, S. G. (2017). Structural and functional architecture of AMPA-Type glutamate receptors and their auxiliary proteins. Neuron 94, 713-730. doi: 10.1016/j.neuron.2017.04.009

Grunwald, M. E., and Kaplan, J. M. (2003). Mutations in the ligand-binding and pore domains control exit of glutamate receptors from the endoplasmic reticulum in C. elegans. Neuropharmacology 45, 768-776. doi: 10.1016/s00283908(03)00274-0

Guntupalli, S., Widagdo, J., Anggono, V., Guntupalli, S., Widagdo, J., and Anggono, V. (2016). Amyloid- $\beta$-induced dysregulation of AMPA receptor trafficking. Neural Plast. 2016:3204519. doi: 10.1155/2016/3204519

Haering, S., Tapken, D., Pahl, S., and Hollmann, M. (2014). Auxiliary subunits: shepherding AMPA receptors to the plasma membrane. Membranes 4, 469-490. doi: 10.3390/membranes4030469

Hanley, J. G., Khatri, L., Hanson, P. I., and Ziff, E. B. (2002). NSF ATPase and $\alpha-/ \beta$-SNAPs disassemble the AMPA receptor-PICK1 complex. Neuron 34 , 53-67. doi: 10.1016/s0896-6273(02)00638-4

Hanus, C., and Schuman, E. M. (2013). Proteostasis in complex dendrites. Nat. Rev. Neurosci. 14, 638-648. doi: 10.1038/nrn3546

Hayashi, Y., Shi, S. H., Esteban, J. A., Piccini, A., Poncer, J. C., and Malinow, R. (2000). Driving AMPA receptors into synapses by LTP and CaMKII: requirement for GluR1 and PDZ domain interaction. Science 287, 2262-2267. doi: $10.1126 /$ science.287.5461.2262

He, K., Song, L., Cummings, L. W., Goldman, J., Huganir, R. L., and Lee, H.K. (2009). Stabilization of $\mathrm{Ca}^{2+}$-permeable AMPA receptors at perisynaptic sites by GluR1-S845 phosphorylation. Proc. Natl. Acad. Sci. U S A 106, 20033-20038. doi: 10.1073/pnas.0910338106

Henley, J. M., and Wilkinson, K. A. (2016). Synaptic AMPA receptor composition in development, plasticity and disease. Nat. Rev. Neurosci. 17, 337-350. doi: 10.1038/nrn.2016.37

Heo, W. D., Inoue, T., Park, W. S., Kim, M. L., Park, B. O., Wandless, T. J., et al. (2006). $\mathrm{PI}(3,4,5) \mathrm{P}_{3}$ and $\mathrm{PI}(4,5) \mathrm{P}_{2}$ lipids target proteins with polybasic clusters to the plasma membrane. Science 314, 1458-1461. doi: 10.1126/science.1134389

Hicke, L., and Dunn, R. (2003). Regulation of membrane protein transport by ubiquitin and ubiquitin-binding proteins. Annu. Rev. Cell Dev. Biol. 19, 141-172. doi: 10.1146/annurev.cellbio.19.110701.154617

Hirling, H. (2009). Endosomal trafficking of AMPA-type glutamate receptors. Neuroscience 158, 36-44. doi: 10.1016/j.neuroscience.2008.02.057

Howard, M. A., Elias, G. M., Elias, L. A. B., Swat, W., and Nicoll, R. A. (2010). The role of SAP97 in synaptic glutamate receptor dynamics. Proc. Natl. Acad. Sci. U S A 107, 3805-3810. doi: 10.1073/pnas.0914422107

Hsieh, H., Boehm, J., Sato, C., Iwatsubo, T., Tomita, T., Sisodia, S., et al. (2006). AMPAR removal underlies $A \beta$-induced synaptic depression and dendritic spine loss. Neuron 52, 831-843. doi: 10.1016/j.neuron.2006.10.035

Hu, Y. B., Dammer, E. B., Ren, R. J., and Wang, G. (2015). The endosomallysosomal system: from acidification and cargo sorting to neurodegeneration. Transl. Neurodegener. 4:18. doi: 10.1186/s40035-015-0041-1

Huotari, J., and Helenius, A. (2011). Endosome maturation. EMBO J. 30, 3481-3500. doi: 10.1038/emboj.2011.286

Hussain, N. K., Diering, G. H., Sole, J., Anggono, V., and Huganir, R. L. (2014). Sorting Nexin 27 regulates basal and activity-dependent trafficking of AMPARs. Proc. Natl. Acad. Sci. U S A 111, 11840-11845. doi: 10.1073/pnas. 1412415111

Iqbal, K., and Grundke-Iqbal, I. (2008). Alzheimer neurofibrillary degeneration: significance, etiopathogenesis, therapeutics and prevention: Alzheimer review series. J. Cell. Mol. Med. 12, 38-55. doi: 10.1111/j.1582-4934.2008.00225.x
Isaac, J. T. R., Ashby, M., and McBain, C. J. (2007). The role of the GluR2 subunit in AMPA receptor function and synaptic plasticity. Neuron 54, 859-871. doi: 10.1016/j.neuron.2007.06.001

Jackson, A. C., and Nicoll, R. A. (2011). Stargazin (TARP $\gamma$-2) is required for compartment-specific AMPA receptor trafficking and synaptic plasticity in cerebellar stellate cells. J. Neurosci. 31, 3939-3952. doi: 10.1523/jneurosci.513410.2011

Jacobi, E., and von Engelhardt, J. (2018). AMPA receptor complex constituents: control of receptor assembly, membrane trafficking and subcellular localization. Mol. Cell. Neurosci. 91, 67-75. doi: 10.1016/j.mcn.2018. 05.008

Jiang, Y., Mullaney, K. A., Peterhoff, C. M., Che, S., Schmidt, S. D., BoyerBoiteau, A., et al. (2010). Alzheimer's-related endosome dysfunction in Down syndrome is A $\beta$-independent but requires APP and is reversed by BACE- 1 inhibition. Proc. Natl. Acad. Sci. U S A 107, 1630-1635. doi: 10.1073/pnas. 0908953107

Jin, W., Ge, W. P., Xu, J., Cao, M., Peng, L., Yung, W., et al. (2006). Lipid binding regulates synaptic targeting of PICK1, AMPA receptor trafficking, and synaptic plasticity. J. Neurosci. 26, 2380-2390. doi: 10.1523/JNEUROSCI.3503-05.2006

Jurado, S., Benoist, M., Lario, A., Knafo, S., Petrok, C. N., and Esteban, J. A. (2010). PTEN is recruited to the postsynaptic terminal for NMDA receptor-dependent long-term depression. EMBO J. 29, 2827-2840. doi: 10.1038/emboj.2010.160

Keith, D. J., Sanderson, J. L., Gibson, E. S., Woolfrey, K. M., Robertson, H. R., Olszewski, K., et al. (2012). Palmitoylation of A-kinase anchoring protein $79 / 150$ regulates dendritic endosomal targeting and synaptic plasticity mechanisms. J. Neurosci. 32, 7119-7136. doi: 10.1523/JNEUROSCI.078412.2012

Kennedy, M. J., and Ehlers, M. D. (2006). Organelles and trafficking machinery for postsynaptic plasticity. Annu. Rev. Neurosci. 29, 325-362. doi: 10.1146/annurev.neuro.29.051605.112808

Kennedy, M. J., Davison, I. G., Robinson, C. G., and Ehlers, M. D. (2010). Syntaxin-4 defines a domain for activity-dependent exocytosis in dendritic spines. Cell 141, 524-535. doi: 10.1016/j.cell.2010.02.042

Kim, C. H., Chung, H. J., Lee, H. K., and Huganir, R. L. (2001). Interaction of the AMPA receptor subunit GluR2/3 with PDZ domains regulates hippocampal long-term depression. Proc. Natl. Acad. Sci. U S A 98, 11725-11730. doi: 10.1073/pnas.211132798

Kneussel, M., and Hausrat, T. J. (2016). Postsynaptic neurotransmitter receptor reserve pools for synaptic potentiation. Trends Neurosci. 39, 170-182. doi: 10.1016/j.tins.2016.01.002

Korolchuk, V. I., Menzies, F. M., and Rubinsztein, D. C. (2010). Mechanisms of cross-talk between the ubiquitin-proteasome and autophagy-lysosome systems. FEBS Lett. 584, 1393-1398. doi: 10.1016/j.febslet.2009.12.047

Koszegi, Z., Fiuza, M., and Hanley, J. G. (2017). Endocytosis and lysosomal degradation of GluA2/3 AMPARs in response to oxygen/glucose deprivation in hippocampal but not cortical neurons. Sci. Rep. 7:12318. doi: 10.1038/s41598017-12534-w

Kunde, S.-A., Rademacher, N., Zieger, H., and Shoichet, S. A. (2017). Protein kinase $\mathrm{C}(\mathrm{PKC})$ regulates AMPA receptor auxiliary protein Shisa9/CKAMP44 through interactions with neuronal scaffold PICK1. FEBS Open Bio 7, 1234-1245. doi: 10.1002/2211-5463.12261

LaFerla, F. M. (2002). Calcium dyshomeostasis and intracellular signalling in Alzheimer's disease. Nat. Rev. Neurosci. 3, 862-872. doi: 10.1038/ nrn960

Lai, C., Xie, C., Shim, H., Chandran, J., Howell, B. W., and Cai, H. (2009). Regulation of endosomal motility and degradation by amyotrophic lateral sclerosis 2/alsin. Mol. Brain 2:23. doi: 10.1186/1756-6606-2-23

Lane, R. F., St George-Hyslop, P., Hempstead, B. L., Small, S. A., Strittmatter, S. M., and Gandy, S. (2012). Vps10 family proteins and the retromer complex in aging-related neurodegeneration and diabetes. J. Neurosci. 32, 14080-14086. doi: 10.1523/JNEUROSCI.3359-12.2012

Lee, C., and Goldberg, J. (2010). Structure of coatomer cage proteins and the relationship among COPI, COPII, and clathrin vesicle coats. Cell 142, 123-132. doi: 10.1016/j.cell.2010.05.030

Lee, H. K., Kameyama, K., Huganir, R. L., and Bear, M. F. (1998). NMDA induces long-term synaptic depression and dephosphorylation of the GluR1 subunit of AMPA receptors in hippocampus. Neuron 21, 1151-1162. doi: 10.1016/s08966273(00)80632-7 
Lee, H. W., Kim, Y., Han, K., Kim, H., and Kim, E. (2010). The phosphoinositide 3-phosphatase MTMR2 interacts with PSD-95 and maintains excitatory synapses by modulating endosomal traffic. J. Neurosci. 30, 5508-5518. doi: 10.1523/JNEUROSCI.4283-09.2010

Lee, M. J., Lee, J. H., and Rubinsztein, D. C. (2013). Tau degradation: the ubiquitinproteasome system versus the autophagy-lysosome system. Prog. Neurobiol. 105, 49-59. doi: 10.1016/j.pneurobio.2013.03.001

Lee, S. H., Liu, L., Wang, Y. T., and Sheng, M. (2002). Clathrin adaptor AP2 and NSF interact with overlapping sites of GluR2 and play distinct roles in AMPA receptor trafficking and hippocampal LTD. Neuron 36, 661-674. doi: $10.1016 / \mathrm{s} 0896-6273(02) 01024-3$

Lee, S. H., Simonetta, A., and Sheng, M. (2004). Subunit rules governing the sorting of internalized AMPA receptors in hippocampal neurons. Neuron 43, 221-236. doi: $10.1016 /$ j.neuron.2004.06.015

Lee, H. K., Takamiya, K., Han, J. S., Man, H., Kim, C. H., Rumbaugh, G., et al. (2003). Phosphorylation of the AMPA receptor GluR1 subunit is required for synaptic plasticity and retention of spatial memory. Cell 112, 631-643. doi: 10.1016/s0092-8674(03)00122-3

Lee, H.-K., Takamiya, K., He, K., Song, L., and Huganir, R. L. (2010). Specific roles of AMPA receptor subunit GluR1 (GluA1) phosphorylation sites in regulating synaptic plasticity in the CA1 region of hippocampus. J. Neurophysiol. 103, 479-489. doi: 10.1152/jn.00835.2009

Leonard, A. S., Davare, M. A., Horne, M. C., Garner, C. C., and Hell, J. W. (1998). SAP97 is associated with the $\alpha$-amino-3-hydroxy-5-methylisoxazole4-propionic acid receptor GluR1 subunit. J. Biol. Chem. 273, 19518-19524. doi: 10.1074/jbc.273.31.19518

Lin, A., Hou, Q., Jarzylo, L., Amato, S., Gilbert, J., Shang, F., et al. (2011). Nedd4mediated AMPA receptor ubiquitination regulates receptor turnover and trafficking. J. Neurochem. 119, 27-39. doi: 10.1111/j.1471-4159.2011.07221.x

Lin, D.-T., and Huganir, R. L. (2007). PICK1 and phosphorylation of the glutamate receptor 2 (GluR2) AMPA receptor subunit regulates GluR2 recycling after NMDA receptor-induced internalization. J. Neurosci. 27, 13903-13908. doi: 10.1523/JNEUROSCI.1750-07.2007

Lin, A., and Man, H. Y. (2014). Endocytic adaptor epidermal growth factor receptor substrate 15 (Eps15) is involved in the trafficking of ubiquitinated $\alpha$ amino-3-hydroxy-5-methyl-4-isoxazolepropionic acid receptors. J. Biol. Chem. 289, 24652-24664. doi: 10.1074/jbc.M114.582114

Liu, S. J., Gasperini, R., Foa, L., and Small, D. H. (2010). Amyloid- $\beta$ decreases cell-surface AMPA receptors by increasing intracellular calcium and phosphorylation of GluR2. J. Alzheimers Dis. 21, 655-666. doi: 10.3233/jad2010-091654

Liu, M., Lewis, L. D., Shi, R., Brown, E. N., and Xu, W. (2014). Differential requirement for NMDAR activity in SAP97-mediated regulation of the number and strength of glutamatergic AMPAR-containing synapses. J. Neurophysiol. 111, 648-658. doi: 10.1152/jn.00262.2013

Liu, B., Liao, M., Mielke, J. G., Ning, K., Chen, Y., Li, L., et al. (2006). Ischemic insults direct glutamate receptor subunit 2-lacking AMPA receptors to synaptic sites. J. Neurosci. 26, 5309-5319. doi: 10.1523/JNEUROSCI.0567-06.2006

Loo, L. S., Tang, N., Al-Haddawi, M., Dawe, G. S., and Hong, W. (2014). A role for sorting nexin 27 in AMPA receptor trafficking. Nat. Commun. 5:3176. doi: $10.1038 /$ ncomms 4176

Lu, Y., Allen, M., Halt, A. R., Weisenhaus, M., Dallapiazza, R. F., Hall, D. D., et al. (2007). Age-dependent requirement of AKAP150-anchored PKA and GluR2lacking AMPA receptors in LTP. EMBO J. 26, 4879-4890. doi: 10.1038/sj. emboj.7601884

Lu, J., Helton, T. D., Blanpied, T. A., Rácz, B., Newpher, T. M., Weinberg, R. J., et al. (2007). Postsynaptic positioning of endocytic zones and AMPA receptor cycling by physical coupling of dynamin-3 to homer. Neuron 55, 874-889. doi: 10.1016/j.neuron.2007.06.041

Lu, W., Khatri, L., and Ziff, E. B. (2014). Trafficking of $\alpha$-amino-3-hydroxy5-methyl-4-isoxazolepropionic acid receptor (AMPA) receptor subunit GluA2 from the endoplasmic reticulum is stimulated by a complex containing $\mathrm{Ca}^{2+} /$ calmodulin-activated kinase II (CaMKII) and PICK1 protein and by release of $\mathrm{Ca}^{2+}$ from internal stores. J. Biol. Chem. 289, 19218-19230. doi: 10.1074/jbc.M113.511246

Lu, W., and Roche, K. W. (2012). Posttranslational regulation of AMPA receptor trafficking and function. Curr. Opin. Neurobiol. 22, 470-479. doi: 10.1016/j. conb.2011.09.008
Lu, W., Shi, Y., Jackson, A. C., Bjorgan, K., During, M. J., Sprengel, R., et al. (2009). Subunit composition of synaptic AMPA receptors revealed by a single-cell genetic approach. Neuron 62, 254-268. doi: 10.1016/j.neuron.2009.02.027

Lussier, M. P., Herring, B. E., Nasu-Nishimura, Y., Neutzner, A., Karbowski, M., Youle, R. J., et al. (2012). Ubiquitin ligase RNF167 regulates AMPA receptormediated synaptic transmission. Proc. Natl. Acad. Sci. U S A 109, 19426-19431. doi: 10.1073/pnas.1217477109

Lussier, M. P., Nasu-Nishimura, Y., and Roche, K. W. (2011). Activity-dependent ubiquitination of the AMPA receptor subunit GluA2. J. Neurosci. 31, 3077-3081. doi: 10.1523/JNEUROSCI.5944-10.2011

Malinow, R., and Malenka, R. C. (2002). AMPA receptor trafficking and synaptic plasticity. Annu. Rev. Neurosci. 25, 103-126. doi: 10.1146/annurev.neuro.25. 112701.142758

Man, H.-Y., Lin, J. W., Ju, W. H., Ahmadian, G., Liu, L., Becker, L. E., et al. (2000). Regulation of AMPA receptor-mediated synaptic transmission by clathrindependent receptor internalization. Neuron 25, 649-662. doi: 10.1016/s08966273(00)81067-3

Man, H. Y., Wang, Q., Lu, W. Y., Ju, W., Ahmadian, G., Liu, L., et al. (2003). Activation of PI3-kinase is required for AMPA receptor insertion during LTP of mEPSCs in cultured hippocampal neurons. Neuron 38, 611-624. doi: 10.1016/s0896-6273(03)00228-9

Mao, L., Takamiya, K., Thomas, G., Lin, D.-T., and Huganir, R. L. (2010). GRIP1 and 2 regulate activity-dependent AMPA receptor recycling via exocyst complex interactions. Proc. Natl. Acad. Sci. U S A 107, 19038-19043. doi: 10.1073/pnas. 1013494107

Matsuda, S., Kakegawa, W., Budisantoso, T., Nomura, T., Kohda, K., and Yuzaki, M. (2013). Stargazin regulates AMPA receptor trafficking through adaptor protein complexes during long-term depression. Nat. Commun. 4:2759. doi: $10.1038 /$ ncomms 3759

Mattson, M. P., Lovell, M. A., Ehmann, W. D., and Markesbery, W. R. (1993). Comparison of the effects of elevated intracellular aluminum and calcium levels on neuronal survival and tau immunoreactivity. Brain Res. 602, 21-31. doi: 10.1016/0006-8993(93)90236-g

Maxfield, F., and McGraw, T. (2004). Endocytic recycling. Nat. Rev. Mol. Cell Biol. 5, 121-132. doi: 10.1038/nrm1315

Mayford, M., Siegelbaum, S. A., and Kandel, E. R. (2012). Synapses and memory storage. Cold Spring Harb. Perspect. Biol. 4:a005751. doi: 10.1101/cshperspect. a005751

Mazzulli, J. R., Xu, Y. H., Sun, Y., Knight, A. L., McLean, P. J., Caldwell, G. A., et al. (2011). Gaucher disease glucocerebrosidase and $\alpha$-synuclein form a bidirectional pathogenic loop in synucleinopathies. Cell 146, 37-52. doi: 10.1016/j.cell.2011.06.001

McCartney, A. J., Zolov, S. N., Kauffman, E. J., Zhang, Y., Strunk, B. S., Weisman, L. S., et al. (2014). Activity-dependent $\mathrm{PI}(3,5) \mathrm{P}_{2}$ synthesis controls AMPA receptor trafficking during synaptic depression. Proc. Natl. Acad. Sci. U $S$ A 111, E4896-E4905. doi: 10.1073/pnas.1411117111

Mignogna, M. L., Giannandrea, M., Gurgone, A., Fanelli, F., Raimondi, F., Mapelli, L., et al. (2015). The intellectual disability protein RAB39B selectively regulates GluA2 trafficking to determine synaptic AMPAR composition. Nat. Commun. 6:6504. doi: 10.1038/ncomms7504

Moult, P. R., Cross, A., Santos, S. D., Carvalho, A.-L., Lindsay, Y., Connolly, C. N., et al. (2010). Leptin regulates AMPA receptor trafficking via PTEN inhibition. J. Neurosci. 30, 4088-4101. doi: 10.1523/JNEUROSCI.3614-09.2010

Muhammad, A., Flores, I., Zhang, H., Yu, R., Staniszewski, A., Planel, E., et al. (2008). Retromer deficiency observed in Alzheimer's disease causes hippocampal dysfunction, neurodegeneration, and A accumulation. Proc. Natl. Acad. Sci. U S A 105, 7327-7332. doi: 10.1073/pnas.08025 45105

Munsie, L. N., Milnerwood, A. J., Seibler, P., Beccano-Kelly, D. A., Tatarnikov, I., Khinda, J., et al. (2015). Retromer-dependent neurotransmitter receptor trafficking to synapses is altered by the Parkinson's disease VPS35 mutation p.D620N. Hum. Mol. Genet. 24, 1691-1703. doi: 10.1093/hmg/ ddu582

Murray, D. H., Jahnel, M., Lauer, J., Avellaneda, M. J., Brouilly, N., Cezanne, A., et al. (2016). An endosomal tether undergoes an entropic collapse to bring vesicles together. Nature 537, 107-111. doi: 10.1038/nature19326

Nakagawa, T., Futai, K., Lashuel, H. A., Lo, I., Okamoto, K., Walz, T., et al. (2004). Quaternary structure, protein dynamics, and synaptic function 
of SAP97 controlled by L27 domain interactions. Neuron 44, 453-467. doi: 10.1016/j.neuron.2004.10.012

Nash, J. E., Appleby, V. J., Corrêa, S. A. L., Wu, H., Fitzjohn, S. M., Garner, C. C., et al. (2010). Disruption of the interaction between myosin VI and SAP97 is associated with a reduction in the number of AMPARs at hippocampal synapses. J. Neurochem. 112, 677-690. doi: 10.1111/j.1471-4159.2009. 06480.x

Nedelsky, N. B., Todd, P. K., and Taylor, J. P. (2008). Autophagy and the ubiquitinproteasome system: collaborators in neuroprotection. Biochim. Biophys. Acta 1782, 691-699. doi: 10.1016/j.bbadis.2008.10.002

Nicot, A. S., and Laporte, J. (2008). Endosomal phosphoinositides and human diseases. Traffic 9, 1240-1249. doi: 10.1111/j.1600-0854.2008.00754.x

O’Hare Doig, R. L., Bartlett, C. A., Smith, N. M., Hodgetts, S. I., Dunlop, S. A., Hool, L., et al. (2016). Specific combinations of ion channel inhibitors reduce excessive $\mathrm{Ca}^{2+}$ influx as a consequence of oxidative stress and increase neuronal and glial cell viability in vitro. Neuroscience 339, 450-462. doi: 10.1016/j.neuroscience.2016.10.005

Oh, M. C., Derkach, V. A., Guire, E. S., and Soderling, T. R. (2006). Extrasynaptic membrane trafficking regulated by GluR1 serine 845 phosphorylation primes AMPA receptors for long-term potentiation. J. Biol. Chem. 281, 752-758. doi: 10.1074/jbc.m509677200

Opazo, P., Sainlos, M., and Choquet, D. (2012). Regulation of AMPA receptor surface diffusion by PSD-95 slots. Curr. Opin. Neurobiol. 22, 453-460. doi: 10.1016/j.conb.2011.10.010

Osten, P., Khatri, L., Perez, J. L., Köhr, G., Giese, G., Daly, C., et al. (2000). Mutagenesis reveals a role for ABP/GRIP binding to GluR2 in synaptic surface accumulation of the AMPA receptor. Neuron 27, 313-325. doi: 10.1016/s08966273(00)00039-8

Osterweil, E., Wells, D. G., and Mooseker, M. S. (2005). A role for myosin VI in postsynaptic structure and glutamate receptor endocytosis. J. Cell Biol. 168, 329-338. doi: 10.1083/jcb.200410091

Outeiro, T. F., and Lindquist, S. (2003). Yeast cells provide insight into $\alpha$-synuclein biology and pathobiology. Science 302, 1772-1775. doi: 10.1126/science. 1090439

Padamsey, Z., McGuinness, L., Bardo, S. J., Reinhart, M., Tong, R., Hedegaard, A., et al. (2017). Activity-dependent exocytosis of lysosomes regulates the structural plasticity of dendritic spines. Neuron 93, 132-146. doi: 10.1016/j. neuron.2016.11.013

Pan, L., Wu, H., Shen, C., Shi, Y., Jin, W., Xia, J., et al. (2007). Clustering and synaptic targeting of PICK1 requires direct interaction between the PDZ domain and lipid membranes. EMBO J. 26, 4576-4587. doi: 10.1038/sj.emboj. 7601860

Park, M., Penick, E. C., Edwards, J. G., Kauer, J. A., and Ehlers, M. D. (2004). Recycling endosomes supply AMPA receptors for LTP. Science 305, 1972-1975. doi: 10.1126/science.1102026

Park, M., Salgado, J. M., Ostroff, L., Helton, T. D., Robinson, C. G., Harris, K. M., et al. (2006). Plasticity-induced growth of dendritic spines by exocytic trafficking from recycling endosomes. Neuron 52, 817-830. doi: 10.1016/j. neuron.2006.09.040

Parkinson, G. T., Chamberlain, S. E. L., Jaafari, N., Turvey, M., Mellor, J. R., and Hanley, J. G. (2018). Cortactin regulates endo-lysosomal sorting of AMPARs via direct interaction with GluA2 subunit. Sci. Rep. 8:4155. doi: 10.1038/s41598018-22542-z

Passafaro, M., Piëch, V., and Sheng, M. (2001). Subunit-specific temporal and spatial patterns of AMPA receptor exocytosis in hippocampal neurons. Nat. Neurosci. 4, 917-926. doi: 10.1038/nn0901-917

Patrick, G. N., Bingol, B., Weld, H. A., and Schuman, E. M. (2003). Ubiquitinmediated proteasome activity is required for agonist-induced endocytosis of GluRs. Curr. Biol. 13, 2073-2081. doi: 10.1016/j.cub.2003.10.028

Pellegrini-Giampietro, D. E., Zukin, R. S., Bennett, M. V., Cho, S., and Pulsinelli, W. A. (1992). Switch in glutamate receptor subunit gene expression in CA1 subfield of hippocampus following global ischemia in rats. Proc. Natl. Acad. Sci. U S A 89, 10499-10503. doi: 10.1073/pnas.89.21. 10499

Pierrot, N., Santos, S. F., Feyt, C., Morel, M., Brion, J. P., and Octave, J. N. (2006). Calcium-mediated transient phosphorylation of tau and amyloid precursor protein followed by intraneuronal amyloid- $\beta$ accumulation. J. Biol. Chem. 281, 39907-39914. doi: 10.1074/jbc.m606015200
Piper, R. C., and Luzio, J. P. (2007). Ubiquitin-dependent sorting of integral membrane proteins for degradation in lysosomes. Curr. Opin. Cell Biol. 19, 459-465. doi: 10.1016/j.ceb.2007.07.002

Puthenveedu, M. A., Lauffer, B., Temkin, P., Vistein, R., Carlton, P., Thorn, K., et al. (2010). Sequence-dependent sorting of recycling proteins by actinstabilized endosomal microdomains. Cell 143, 761-773. doi: 10.1016/j.cell. 2010.10.003

Rabenstein, M., Peter, F., Joost, S., Trilck, M., Rolfs, A., and Frech, M. J. (2017). Decreased calcium flux in Niemann-Pick type C1 patient-specific iPSC-derived neurons due to higher amount of calcium-impermeable AMPA receptors. Mol. Cell. Neurosci. 83, 27-36. doi: 10.1016/j.mcn.2017.06.007

Reinders, N. R., Pao, Y., Renner, M. C., da Silva-Matos, C. M., Lodder, T. R., Malinow, R., et al. (2016). Amyloid- $\beta$ effects on synapses and memory require AMPA receptor subunit GluA3. Proc. Natl. Acad. Sci. U S A 113, E6526-E6534. doi: $10.1073 /$ pnas. 1614249113

Richmond, S. A., Irving, A. J., Molnár, E., McIlhinney, R. A. J., Michelangeli, F., Henley, J. M., et al. (1996). Localization of the glutamate receptor subunit GluR1 on the surface of living and within cultured hippocampal neurons. Neuroscience 75, 69-82. doi: 10.1016/0306-4522(96) 00217-5

Rodrigues, E. M., Scudder, S. L., Goo, M. S., and Patrick, G. N. (2016). A-induced synaptic alterations require the E3 ubiquitin ligase nedd4-1. J. Neurosci. 36, 1590-1595. doi: 10.1523/JNEUROSCI.2964-15.2016

Sanderson, J. L., and Dell'Acqua, M. L. (2011). AKAP signaling complexes in regulation of excitatory synaptic plasticity. Neuroscientist 17, 321-336. doi: $10.1177 / 1073858410384740$

Sanderson, J. L., Scott, J. D., and Dell'Acqua, M. L. (2018). Control of homeostatic synaptic plasticity by AKAP-anchored kinase and phosphatase regulation of $\mathrm{Ca}^{2+}$-permeable AMPA receptors. J. Neurosci. 38, 2363-2876. doi: 10.1523/JNEUROSCI.2362-17.2018

Savas, J. N., Ribeiro, L. F., Wierda, K. D., Wright, R., DeNardo-Wilke, L. A., Rice, H. C., et al. (2015). The sorting receptor SorCS1 regulates trafficking of neurexin and AMPA receptors. Neuron 87, 764-780. doi: 10.1016/j.neuron. 2015.08.007

Schlüter, O. M., Xu, W., and Malenka, R. C. (2006). Alternative N-terminal domains of PSD-95 and SAP97 govern activity-dependent regulation of synaptic AMPA receptor function. Neuron 51, 99-111. doi: 10.1016/j.neuron. 2006.05.016

Schnell, E., Sizemore, M., Karimzadegan, S., Chen, L., Bredt, D. S., and Nicoll, R. A. (2002). Direct interactions between PSD-95 and stargazin control synaptic AMPA receptor number. Proc. Natl. Acad. Sci. U S A 99, 13902-13907. doi: 10.1073/pnas.172511199

Schreij, A. M. A., Fon, E. A., and McPherson, P. S. (2016). Endocytic membrane trafficking and neurodegenerative disease. Cell. Mol. Life Sci. 73, 1529-1545. doi: 10.1007/s00018-015-2105-x

Schwarz, L. A., Hall, B. J., and Patrick, G. N. (2010). Activity-dependent ubiquitination of GluA1 mediates a distinct AMPA receptor endocytosis and sorting pathway. J. Neurosci. 30, 16718-16729. doi: 10.1523/JNEUROSCI.368610.2010

Schwenk, J., Baehrens, D., Haupt, A., Bildl, W., Boudkkazi, S., Roeper, J., et al. (2014). Regional diversity and developmental dynamics of the AMPA-receptor proteome in the mammalian brain. Neuron 84, 41-54. doi: 10.1016/j.neuron. 2014.08.044

Schwenk, J., Harmel, N., Brechet, A., Zolles, G., Berkefeld, H., Müller, C. S., et al. (2012). High-resolution proteomics unravel architecture and molecular diversity of native AMPA receptor complexes. Neuron 74, 621-633. doi: 10.1016/j.neuron.2012.03.034

Scott, C. C., Vacca, F., and Gruenberg, J. (2014). Endosome maturation, transport and functions. Semin. Cell Dev. Biol. 31, 2-10. doi: 10.1016/j.semcdb.2014. 03.034

Scudder, S. L., Goo, M. S., Cartier, A. E., Molteni, A., Schwarz, L. A., Wright, R., et al. (2014). Synaptic strength is bidirectionally controlled by opposing activity-dependent regulation of Nedd4-1 and USP8. J. Neurosci. 34, 16637-16649. doi: 10.1523/JNEUROSCI.2452-14.2014

Seebohm, G., Neumann, S., Theiss, C., Novkovic, T., Hill, E. V., Tavaré, J. M., et al. (2012). Identification of a novel signaling pathway and its relevance for GluA1 recycling. PLoS One 7:e33889. doi: 10.1371/journal.pone.00 33889 
Selak, S., Paternain, A. V., Fritzler, M. J., and Lerma, J. (2006). Human autoantibodies against early endosome antigen-1 enhance excitatory synaptic transmission. Neuroscience 143, 953-964. doi: 10.1016/j.neuroscience.2006. 10.014

Selkoe, D. J., and Hardy, J. (2016). The amyloid hypothesis of Alzheimer's disease at 25 years. EMBO Mol. Med. 8, 595-608. doi: 10.15252/emmm.201606210

Setou, M., Seog, D.-H., Tanaka, Y., Kanai, Y., Takei, Y., Kawagishi, M., et al. (2002). Glutamate-receptor-interacting protein GRIP1 directly steers kinesin to dendrites. Nature 417, 83-87. doi: 10.1038/nature743

Shepherd, J. D., and Huganir, R. L. (2007). The cell biology of synaptic plasticity: AMPA receptor trafficking. Annu. Rev. Cell Dev. Biol. 23, 613-643. doi: 10.1146/annurev.cellbio.23.090506.123516

Shi, S. H., Hayashi, Y., Esteban, J. A., and Malinow, R. (2001). Subunit-specific rules governing AMPA receptor trafficking to synapses in hippocampal pyramidal neurons. Cell 105, 331-343. doi: 10.1016/s0092-8674(01) 00321-x

Simonsen, A., Lippé, R., Christoforidis, S., Gaullier, J. M., Brech, A., Callaghan, J., et al. (1998). EEA1 links PI(3)K function to Rab5 regulation of endosome fusion. Nature 394, 494-498. doi: 10.1038/28879

Spencer, B., Kim, C., Gonzalez, T., Bisquertt, A., Patrick, C., Rockenstein, E., et al. (2015). $\alpha$-synuclein interferes with the ESCRT-III complex contributing to the pathogenesis of Lewy body disease. Hum. Mol. Genet. 25, 1100-1115. doi: $10.1093 / \mathrm{hmg} / \mathrm{ddv} 633$

Steinberg, J. P., Takamiya, K., Shen, Y., Xia, J., Rubio, M. E., Yu, S., et al. (2006). Targeted in vivo mutations of the AMPA receptor subunit GluR2 and its interacting protein PICK1 eliminate cerebellar long-term depression. Neuron 49, 845-860. doi: 10.1016/j.neuron.2006.02.025

Steiner, P., Alberi, S., Kulangara, K., Yersin, A., Sarria, J.-C. F., Regulier, E., et al. (2005). Interactions between NEEP21, GRIP1 and GluR2 regulate sorting and recycling of the glutamate receptor subunit GluR2. EMBO J. 24, 2873-2884. doi: 10.1038/sj.emboj.7600755

Steinmetz, C. C., Tatavarty, V., Sugino, K., Shima, Y., Joseph, A., Lin, H., et al. (2016). Upregulation of $\mu 3 \mathrm{~A}$ drives homeostatic plasticity by rerouting AMPAR into the recycling endosomal pathway. Cell Rep. 16, 2711-2722. doi: 10.1016/j.celrep.2016.08.009

Sumioka, A. (2013). Auxiliary subunits provide new insights into regulation of AMPA receptor trafficking. J. Biochem. 153, 331-337. doi: 10.1093/jb/ mvt015

Szíber, Z., Liliom, H., Morales, C. O. O., Ignácz, A., Rátkai, A. E., Ellwanger, K., et al. (2017). Ras and Rab interactor 1 controls neuronal plasticity by coordinating dendritic filopodial motility and AMPA receptor turnover. Mol. Biol. Cell 28, 285-295. doi: 10.1091/mbc.e16-07-0526

Takahashi, R. H., Almeida, C. G., Kearney, P. F., Yu, F., Lin, M. T., Milner, T. A., et al. (2004). Oligomerization of Alzheimer's $\beta$-amyloid within processes and synapses of cultured neurons and brain. J. Neurosci. 24, 3592-3599. doi: 10.1523/JNEUROSCI.5167-03.2004

Takahashi, R. H., Milner, T. A., Li, F., Nam, E. E., Edgar, M. A., Yamaguchi, H., et al. (2002). Intraneuronal Alzheimer A $\beta 42$ accumulates in multivesicular bodies and is associated with synaptic pathology. Am. J. Pathol. 161, 1869-1879. doi: 10.1016/s0002-9440(10)64463-x

Takeuchi, T., Duszkiewicz, A. J., and Morris, R. G. M. (2013). The synaptic plasticity and memory hypothesis: encoding, storage and persistence. Philos. Trans. R. Soc. Lond. B Biol. Sci. 369:20130288. doi: 10.1098/rstb.2013.0288

Tan, X., Thapa, N., Choi, S., and Anderson, R. A. (2015). Emerging roles of PtdIns(4,5)P2-beyond the plasma membrane. J. Cell Sci. 128, 4047-4056. doi: $10.1242 /$ jcs. 175208

Tao-Cheng, J.-H., Crocker, V. T., Winters, C. A., Azzam, R., Chludzinski, J., and Reese, T. S. (2011). Trafficking of AMPA receptors at plasma membranes of hippocampal neurons. J. Neurosci. 31, 4834-4843. doi: 10.1523/JNEUROSCI. 4745-10.2011

Teasdale, R. D., and Collins, B. M. (2012). Insights into the PX (phox-homology) domain and SNX (sorting nexin) protein families: structures, functions and roles in disease. Biochem. J. 441, 39-59. doi: 10.1042/BJ20111226

Temkin, P., Morishita, W., Goswami, D., Arendt, K., Chen, L., and Malenka, R. (2017). The retromer supports AMPA receptor trafficking during LTP. Neuron 94, 74.e5-82.e5. doi: 10.1016/j.neuron.2017.03.020

Terashima, A., Cotton, L., Dev, K. K., Meyer, G., Zaman, S., Duprat, F., et al. (2004). Regulation of synaptic strength and AMPA receptor subunit composition by PICK1. J. Neurosci. 24, 5381-5390. doi: 10.1523/JNEUROSCI 4378-03.2004

Terashima, A., Pelkey, K. A., Rah, J. C., Suh, Y. H., Roche, K. W., Collingridge, G., et al. (2008). An essential role for PICK1 in NMDA receptor-dependent bidirectional synaptic plasticity. Neuron 57, 872-882. doi: 10.1016/j.neuron. 2008.01.028

Thomas, G., Hayashi, T., Chiu, S. L., Chen, C. M., and Huganir, R. (2012). Palmitoylation by DHHC5/8 targets GRIP1 to dendritic endosomes to regulate AMPA-R trafficking. Neuron 73, 482-496. doi: 10.1016/j.neuron.2011.11.021

Tian, Y., Tang, F. L., Sun, X. D., Wen, L., Mei, L., Tang, B. S., et al. (2015). VPS35deficiency results in an impaired AMPA receptor trafficking and decreased dendritic spine maturation. Mol. Brain 8:70. doi: 10.1186/s13041-015-0156-4

Ting, J. T., Kelley, B. G., Lambert, T. J., Cook, D. G., and Sullivan, J. M. (2007). Amyloid precursor protein overexpression depresses excitatory transmission through both presynaptic and postsynaptic mechanisms. Proc. Natl. Acad. Sci. U S A 104, 353-358. doi: 10.1073/pnas.0608807104

Tomita, S., Adesnik, H., Sekiguchi, M., Zhang, W., Wada, K., Howe, J. R., et al. (2005). Stargazin modulates AMPA receptor gating and trafficking by distinct domains. Nature 435, 1052-1058. doi: 10.1038/nature03624

Ueda, Y. (2014). The role of phosphoinositides in synapse function. Mol. Neurobiol. 50, 821-838. doi: 10.1007/s12035-014-8768-8

van der Sluijs, P., and Hoogenraad, C. C. (2011). New insights in endosomal dynamics and AMPA receptor trafficking. Semin. Cell Dev. Biol. 22, 499-505. doi: 10.1016/j.semcdb.2011.06.008

Volpicelli-Daley, L. A., Gamble, K. L., Schultheiss, C. E., Riddle, D. M., West, A. B., and Lee, V. M.-Y. (2014). Formation of $\alpha$-synuclein Lewy neurite-like aggregates in axons impedes the transport of distinct endosomes. Mol. Biol. Cell 25, 4010-4023. doi: 10.1091/mbc.E14-02-0741

Von Bartheld, C. S., and Altick, A. L. (2011). Multivesicular bodies in neurons: distribution, protein content, and trafficking functions. Prog. Neurobiol. 93 313-340. doi: 10.1016/j.pneurobio.2011.01.003

Wen, Y. D., Sheng, R., Zhang, L. S., Han, R., Zhang, X., Zhang, X. D., et al. (2008) Neuronal injury in rat model of permanent focal cerebral ischemia is associated with activation of autophagic and lysosomal pathways. Autophagy 4, 762-769. doi: 10.4161/auto.6412

Wen, H., Zhan, L., Chen, S., Long, L., and Xu, E. (2017). Rab7 may be a novel therapeutic target for neurologic diseases as a key regulator in autophagy. J. Neurosci. Res. 95, 1993-2004. doi: 10.1002/jnr.24034

Wenthold, R. J., Petralia, R. S., Blahos, J. II., and Niedzielski, A. S. (1996). Evidence for multiple AMPA receptor complexes in hippocampal CA1/CA2 neurons. J. Neurosci. 16, 1982-1989. doi: 10.1523/jneurosci.16-06-01982.1996

Whitcomb, D. J., Hogg, E. L., Regan, P., Piers, T., Narayan, P., Whitehead, G., et al. (2015). Intracellular oligomeric amyloid- $\beta$ rapidly regulates GluA1 subunit of AMPA receptor in the hippocampus. Sci. Rep. 5:10934. doi: 10.1038/srep10934

Widagdo, J., Chai, Y., Ridder, M. C., Chau, Y., Johnson, R. C., Sah, P., et al. (2015). Activity-dependent ubiquitination of gluA1 and gluA2 regulates AMPA receptor intracellular sorting and degradation. Cell Rep. 10, 783-795. doi: 10.1016/j.celrep.2015.01.015

Widagdo, J., Fang, H., Jang, S. E., and Anggono, V. (2016). PACSIN1 regulates the dynamics of AMPA receptor trafficking. Sci. Rep. 6:31070. doi: $10.1038 /$ srep 31070

Wilson, J. M., de Hoop, M., Zorzi, N., Toh, B. H., Dotti, C. G., and Parton, R. G. (2000). EEA1, a tethering protein of the early sorting endosome, shows a polarized distribution in hippocampal neurons, epithelial cells, and fibroblasts. Mol. Biol. Cell 11, 2657-2671. doi: 10.1091/mbc.11.8.2657

Woolfrey, K. M., O’Leary, H., Goodell, D. J., Robertson, H. R., Horne, E. A., Coultrap, S. J., et al. (2018). CaMKII regulates the depalmitoylation and synaptic removal of the scaffold protein AKAP79/150 to mediate structural long-term depression. J. Biol. Chem. 293, 1551-1567. doi: 10.1074/jbc.M117. 813808

Woolfrey, K. M., Sanderson, J. L., and Dell'Acqua, M. L. (2015). The palmitoyl acyltransferase DHHC2 regulates recycling endosome exocytosis and synaptic potentiation through palmitoylation of AKAP79/150. J. Neurosci. 35, 442-456. doi: 10.1523/JNEUROSCI.2243-14.2015

Wu, H., Nash, J. E., Zamorano, P., and Garner, C. C. (2002). Interaction of SAP97 with minus-end-directed actin motor myosin VI: implications for AMPA receptor trafficking. J. Biol. Chem. 277, 30928-30934. doi: 10.1074/jbc. M203735200 
Xu, X., and Pozzo-Miller, L. (2017). EEA1 restores homeostatic synaptic plasticity in hippocampal neurons from Rett syndrome mice. J. Physiol. 595, 5699-5712. doi: $10.1113 /$ JP274450

Yap, C. C., and Winckler, B. (2012). Harnessing the power of the endosome to regulate neural development. Neuron 74, 440-451. doi: 10.1016/j.neuron.2012. 04.015

Yeung, T., Gilbert, G. E., Shi, J., Silvius, J., Kapus, A., and Grinstein, S. (2008). Membrane phosphatidylserine regulates surface charge and protein localization. Science 319, 210-213. doi: 10.1126/science.1152066

Yuan, D., Liu, C., and Hu, B. (2018). Dysfunction of membrane trafficking leads to ischemia-reperfusion injury after transient cerebral ischemia. Transl. Stroke Res. 9, 215-222. doi: 10.1007/s12975-017-0572-0

Zhang, Y., McCartney, A. J., Zolov, S. N., Ferguson, C. J., Meisler, M. H., Sutton, M. A., et al. (2012). Modulation of synaptic function by VAC14, a protein that regulates the phosphoinositides $\mathrm{PI}(3,5) \mathrm{P}_{2}$ and $\mathrm{PI}(5) \mathrm{P}$. EMBO J. 31, 3442-3456. doi: 10.1038/emboj.2012.200

Conflict of Interest Statement: The authors declare that the research was conducted in the absence of any commercial or financial relationships that could be construed as a potential conflict of interest.

Copyright (C) 2018 Parkinson and Hanley. This is an open-access article distributed under the terms of the Creative Commons Attribution License (CC BY). The use, distribution or reproduction in other forums is permitted, provided the original author(s) and the copyright owner(s) are credited and that the original publication in this journal is cited, in accordance with accepted academic practice. No use, distribution or reproduction is permitted which does not comply with these terms. 